\title{
Corrosion fatigue behavior of a Mg-based bulk metallic glass in a simulated physiological environment
}

\author{
Haifei Li ${ }^{\text {a b }}$, Ying Liu ${ }^{\text {a }}$, Shujie Pang ${ }^{\text {a }}$, Peter K. Liaw ${ }^{b}$, Tao Zhang ${ }^{\text {a, * }}$ \\ ${ }^{a}$ Key Laboratory of Aerospace Materials and Performance (Ministry of Education), School of \\ Materials Science and Engineering, Beihang University, Beijing 100191, China \\ ${ }^{\mathrm{b}}$ Department of Materials Science and Engineering, The University of Tennessee, Knoxville, TN \\ 37996-2100, USA
}

\begin{abstract}
:
Due to the superior property profile, Mg-based bulk metallic glasses (BMGs) are potential biodegradable biomaterials. Nevertheless, their corrosion fatigue behavior, which is essential for understanding the mechanical performance under the joint actions of the cyclic loading and the aggressive human body environment, remains unexplored. In the present study, compression-compression fatigue experiments were conducted in air and in a simulated physiological environment to study the fatigue and corrosion fatigue behaviors of $\mathrm{Mg}_{66} \mathrm{Zn}_{30} \mathrm{Ca}_{3} \mathrm{Sr}_{1} \mathrm{BMG}$. The fatigue-endurance limits of $\mathrm{Mg}_{66} \mathrm{Zn}_{30} \mathrm{Ca}_{3} \mathrm{Sr}_{1} \mathrm{BMG}$ in air and in the simulated physiological environment were 370 and $150 \mathrm{MPa}$, respectively, suggesting its qualified fatigue property for biomaterials and the detrimental effect of the corrosive environment on the fatigue resistance. During the fatigue tests, $\mathrm{Mg}_{66} \mathrm{Zn}_{30} \mathrm{Ca}_{3} \mathrm{Sr}_{1} \mathrm{BMG}$ went through peeling-off fractures and then the final fragmented fracture. The corrosion in the simulated physiological environment, which provided easy crack-initiation sites for the peeling-off fractures and the final collapse, was responsible for the inferior fatigue resistance to that in air.
\end{abstract}

Keywords: A. metallic glasses; B. fatigue resistance; B. corrosion; F. microscopy; G. biomedical 


\section{Introduction}

Increasing attention has been paid to magnesium alloys as potential biodegradable biomaterials recently, due to their superior mechanical properties, good biocompatibility and intriguing corrosion/degradation performance [1-5]. However, one major concern against the clinical applications of magnesium alloys is their rapid corrosion/degradation rates [2]. The unsatisfactory degradation behavior results in not only the hydrogen-gas bubbles around the implant, which will retard the healing process and cause tissue necrosis, but also the premature loss of mechanical integrity, which may cause sudden implant failure before the tissue is fully healed $[1,3]$. Emerging as neoteric metallic materials with amorphous structure, Mg-based bulk metallic glasses (BMGs) exhibit an integration of superior mechanical properties and good corrosion resistance [6]. Compared with crystalline $\mathrm{Mg}$ alloys, the enhanced corrosion/degradation performance of Mg-based BMGs brings about the interests of their biomedical applications as orthopedic implants [3, 7-12].

The orthopedic implants usually suffer cyclic loading, such as tension, compression and bending, indicating that the implant may encounter a fatigue failure during their functioning [13]. Taking into consideration of the aggressive human body environment, a well-functioned implant must be able to survive the corrosion fatigue under a condition of cyclic loading and corrosive body fluid [14, 15]. Thus, it is of significance to study the corrosion fatigue behavior of magnesium alloys in the simulated physiological environment. As reported by $\mathrm{Gu}$ et al. [4], the corrosion fatigue strengths of die-cast AZ91D alloy at $10^{6}$ cycles and extruded WE43 alloy at $10^{7}$ cycles tested in the simulated body fluid (SBF) were 20 and $40 \mathrm{MPa}$, respectively, and the low corrosion fatigue strengths were ascribed to the low fatigue strengths in air and the low corrosion resistance which introduced corrosion pits acting as 
crack-initiation sites.

As competitive candidates for biodegradable implant materials, however, the fatigue or corrosion fatigue behaviors of $\mathrm{Mg}$-based $\mathrm{BMGs}$ remain unexplored, to the best of authors' knowledge. In the present work, the fatigue behaviors in air and in a simulated physiological environment of the $\mathrm{Mg}_{66} \mathrm{Zn}_{30} \mathrm{Ca}_{3} \mathrm{Sr}_{1} \mathrm{BMG}$ were investigated to bridge this gap of knowledge. The mechanisms for the fatigue-fracture and the effect of the corrosive environment on the fatigue behavior were discussed. The $\mathrm{Mg}_{66} \mathrm{Zn}_{30} \mathrm{Ca}_{3} \mathrm{Sr}_{1} \mathrm{BMG}$ was selected because of its superior property profile of high glass-forming ability, good mechanical properties, suitable corrosion resistance and favorable biocompatibility [9].

\section{Material and methods}

Alloy ingots with a nominal composition of $\mathrm{Mg}_{66} \mathrm{Zn}_{30} \mathrm{Ca}_{3} \mathrm{Sr}_{1}$ (at.\%), which is denoted as $\mathrm{Sr} 1$ in the following text, were prepared by induction-melting the mixtures of pure metals under an argon atmosphere, using boron-nitride-coated graphite crucibles as melting vessels. Cylindrical rods with a diameter of $3 \mathrm{~mm}$ and a length of $50 \mathrm{~mm}$ were fabricated by copper-mold casting under an argon atmosphere. The amorphous structure of the rods was verified by the X-ray diffraction pattern that shows only broad peaks (Fig. S1 in the Supplementary material).

Uniaxial compression tests and compression-compression fatigue (CCF) tests were conducted on as-cast cylindrical samples of $3 \mathrm{~mm}$ in diameter and $6 \mathrm{~mm}$ in length. These specimens were cut from the cast alloy rods, and the end surfaces were polished with $\mathrm{SiC}$ paper up to 1200 grit.

A computer-controlled Material Testing System (MTS) servohydraulic-testing machine was employed for the uniaxial compression and CCF tests. Compression experiments on quadruplicate samples were performed in air at room temperature (RT) 
with an initial strain rate of $1 \times 10^{-4} \mathrm{~s}^{-1}$. Load-controlled fatigue tests were conducted applied minimum and maximum absolute stresses, respectively) of 0.1 , using a sinusoidal waveform at a frequency of $10 \mathrm{~Hz}$. The maximum absolute stress is denoted as maximum stress in the following text and figures. Corrosion fatigue tests were conducted in a chamber containing 2 liters of phosphate-buffered saline (PBS) solution, which was renewed for each sample. The PBS solution, with a recipe of 8.01 $\mathrm{g} \mathrm{NaCl}, 0.2 \mathrm{~g} \mathrm{KCl}, 1.15 \mathrm{~g} \mathrm{Na}_{2} \mathrm{HPO}_{4}$, and $0.2 \mathrm{~g} \mathrm{KH}_{2} \mathrm{PO}_{4}$ in 1 liter of deionized water, is a commonly used simulated physiological fluid [5]. Each fatigue test was stopped at certain cycles or until the sample completely failed or achieved $10^{7}$ cycles. When sample was completely failed at a specified applied stress level, the number of cycles to failure represented the fatigue lifetime of the sample at that applied stress level. The fatigue strength was defined to be the applied maximum stress at which $10^{7}$ cycles could be achieved.

Fracture morphologies of the samples tested in air and PBS were observed by the scanning electron microscopy (SEM) to identify the fracture mechanisms. Prior to the SEM observation, some samples failed under the corrosion fatigue tests were immersed in chromic acid $\left(\mathrm{CrO}_{3}, 200 \mathrm{~g} / \mathrm{L}\right)$ for $10 \mathrm{~min}$ to remove the corrosion products. Fine powders, which were prepared by gently grinding the as-cast sample or the failed samples in a ceramic mortar with absolute alcohol, were subject to the high resolution transmission electron microscopy (HRTEM) observation to investigate the microstructures.

\section{Results}

\subsection{Stress-life $(S-N)$ behaviors}

The typical compressive stress-strain curve of Sr1 BMG sample with a diameter 
of $3 \mathrm{~mm}$ is shown in Fig. S2 in the Supplementary material. The fracture strength of $\mathrm{Sr} 1 \mathrm{BMG}$ is $785 \pm 30 \mathrm{MPa}$.

The S-N behaviors of Sr1 BMG samples tested in air and PBS, which are depicted by plotting the applied maximum stress $\left(\sigma_{\max }\right)$ as a function of the number of cycles to failure $\left(N_{\mathrm{f}}\right)$, are presented in Fig. 1. The relationship between the applied maximum stress and the fatigue life above the fatigue-endurance limit could be expressed by the following equations:

Fatigue tests in air:

$$
\sigma_{\max }(\mathrm{MPa})=669.8-44.9 \cdot \log N_{\mathrm{f}}
$$

Corrosion fatigue tests in PBS:

$$
\begin{aligned}
& \sigma_{\max }(\mathrm{MPa})=909.6-129.8 \cdot \log N_{\mathrm{f}}, N_{\mathrm{f}}<1.57 \times 10^{5} \\
& \sigma_{\max }(\mathrm{MPa})=440.9-39.6 \cdot \log N_{\mathrm{f}}, 1.57 \times 10^{5} \leq N_{\mathrm{f}}<1 \times 10^{7}
\end{aligned}
$$

According to the S-N curves, Sr1 BMG samples possess much longer fatigue life in air than that in PBS above the fatigue-endurance limit. The fatigue strengths of the Sr1 BMG at $10^{7}$ cycles tested in air and PBS are $370 \mathrm{MPa}$ and $150 \mathrm{MPa}$, respectively. It is clear that the simulated physiological environment exhibits a detrimental effect on the fatigue life of Sr1 BMG, yielding a decrease of $59.5 \%$ to the fatigue strength in PBS, as compared to that in air.

\subsection{Fractography}

Figure 2 shows the fracture morphologies of Sr1 BMG sample failed under the compression test. As shown in Fig. 2a, Sr1 BMG sample collapsed into many small fragments after failure, which is similar to some brittle Mg- and Fe-based BMGs [16, 17]. The fracture surface exhibits three distinct morphologies, including the dominant conchoidal fracture features (Fig. 2b), rock-layer patterns (Fig. 2c), and a mixture of vein-like and river-like patterns (Fig. 2d). The conchoidal fracture features consisting 
of smooth area and tear lines are characteristics of the fracture surface for brittle metallic glasses [16-18]. The rough rock-layer patterns (Fig. 2c) are similar to the compression-fracture surfaces of some $\mathrm{Mg}$ - and Ca-based BMGs [18, 19]. The vein-like patterns [frame (i) in Fig. 2d], which are characteristics of the fracture surface for ductile metallic glasses [20, 21], result from the local heating caused by the release of a high amount of elastic energy stored in the material during deformation [22]. River-like patterns [frame (ii) in Fig. 2d] co-exist with vein-like patterns for some BMGs under uniaxial compression [20, 22]. These river-like features are attributed to the effect of normal stress, which acts locally on a shear plane [20]. The observation of vein-like and river-like patterns suggests that the fracture of the brittle $\mathrm{Sr} 1 \mathrm{BMG}$ proceeded through the local-softening mode on a certain scale. Local melting (indicated by arrows in Fig. 2d), which is caused by the large amount of energy release during the final fracture [23], is observed.

Samples failed under fatigue tests in both air and PBS collapsed into many fragments after the final fragmented fracture, similar to the sample failed under uniaxial compression test. Before the final fracture, the samples under fatigue tests underwent numerous peeling-off fractures that were the shedding of small parts of the sample. The fracture morphologies of the samples fatigue-failed in air at a $\sigma_{\max }$ of 425 $\mathrm{MPa}$ and in PBS at a $\sigma_{\max }$ of $250 \mathrm{MPa}$ are presented in Figs. 3 and 4, respectively. Generally, the samples failed under fatigue tests exhibit conchoidal fracture features (Figs. 3a and 4a), rock-layer patterns (Figs. 3b and 4b), and a mixture of vein-like and river-like patterns (Figs. 3c and 4c). The pore-like flaw and microcrack are observed on the fracture surface, as shown in Fig. 3a. A flat surface film, which was formed during corrosion, is observed on the outer surface, and some nano-sized corrosion pits are also observed on the outer surface, as shown in Fig. 4a. Besides, after cleaning the 
corrosion products, some large-sized corrosion pits and microcracks, which initiated at the corrosion pit, are observed in Fig. $4 \mathrm{~d}$.

Considering the peeling-off fracture feature of the Sr1 BMG during CCF tests, controlled fatigue tests were conducted to study the fracture behavior. A controlled fatigue test was a test which was stopped immediately after the first major peeling-off fracture occurred, and a major peeling-off fracture was defined to be the one penetrating the sample along its long axis, which leaded to the decrease in the cross-sectional area for both end surfaces. A schematic illustration for the configuration of the as-cast sample and the sample after the first major peeling-off fracture is presented in Fig. 5, in which the dotted lines reveal the initial sample geometry. SEM images illustrating the fracture morphologies of the sample after a controlled fatigue test in air at a $\sigma_{\max }$ of $425 \mathrm{MPa}$ are presented in Fig. 6. Figure 6a displays an overview of the sample after the first major peeling-off fracture. The observation of several fracture planes indicates the occurrence of a few regional peeling-off fractures, which contributed to the first major peeling-off fracture. Figures 6b, $6 \mathrm{c}$ and $6 \mathrm{~d}$ are the high-magnification images for regions (i), (ii) and (iii) in Fig. 6a, respectively. Surface features including conchoidal fracture features and river-like patterns are observed in Figs. 6b and 6c. As shown in Fig. 6b, several small-regional peeling-off fractures, which are indicated by the frames, took place near the surface, introducing several abrupt changes in fracture planes. Smooth areas and tear lines are characteristics of the fast-fracture region for the peeling-off fractures. A boundary between smooth areas and river-like patterns is noticed in Fig. $6 \mathrm{c}$, indicating that the release of the cumulative elastic energy caused local softening during the fast-fracture stage. Several flaws on the fracture surface are indicated by arrows in Fig. 6d.

The SEM images illustrating the fracture morphologies of the sample after a 
controlled fatigue test in PBS at a $\sigma_{\max }$ of $250 \mathrm{MPa}$ are presented in Fig. 7. The overview of the sample (Fig. 7a) reveals the occurrence of several regional peeling-off fractures, indicated by a few visible fracture planes. Figures $7 b, 7 c$ and $7 d$ are the high-magnification images for regions (i), (ii) and (iii) in Fig. 7a, respectively. As shown in Fig. 7b, corroded areas are noticed at the edge of the sample (indicated by arrows), and the inset displays a corner [i.e. the region (iv) in Fig. 7a] of the sample which went through severe corrosion. The corroded areas were weak points of the sample and inclined to act as stress concentrators, causing the easy initiation of cracks Features including smooth area and tear lines are observed (Figs. 7b and 7c). Flaws and pore on the fracture surface are noticed in Figs. 7c and 7d, respectively.

The numbers of cycles to the first major peeling-off fracture $\left(N_{\mathrm{p}}\right)$ for the samples under fatigue tests were recorded, and its correlation with the applied maximum stress is presented in Fig. 8. It is clear that for the fatigue tests in both air and PBS, the $N_{\mathrm{p}}$ increases with decreasing the applied maximum stress. Besides, for the samples exhibiting a similar $N_{\mathrm{p}}$, the one tested in air could endure a higher applied stress than the one tested in PBS. It is also noticed that for the samples tested in PBS, the variation of the applied stress as a function of the $N_{\mathrm{p}}$ is similar to that of the $\mathrm{S}-\mathrm{N}$ curve shown in Fig. 1. The mechanisms for these phenomena will be discussed in Section 4.1.

\subsection{Microstructures}

The HRTEM images and selected-area electron diffraction (SAED) patterns characterizing the microstructures of the $\mathrm{Sr} 1 \mathrm{BMG}$ before and after the mechanical tests are presented in Fig. 9. The pre-test sample exhibits a fully amorphous structure without any crystalline feature, which is confirmed by the HRTEM image and the corresponding SAED pattern with a diffused halo ring, as shown in Fig. 9a. The 
formation of nanocrystallites for the samples after the uniaxial compression test (Fig. 9b), fatigue test in air at a $\sigma_{\max }$ of $425 \mathrm{MPa}$ (Fig. 9c) and corrosion fatigue test in PBS at a $\sigma_{\max }$ of $250 \mathrm{MPa}$ (Fig. 9d) are noticed in the HRTEM images and demonstrated by the corresponding SAED patterns with distinct crystalline diffraction spots. The occurrence of nanocrystallization for amorphous samples subject to uniaxial compression has been reported $[24,25]$. It is suggested that a large rise of up to several hundred degrees in local temperature might be created during fracture [26]. Due to the higher Gibbs free energy of amorphous phases than the corresponding crystalline phases [6], amorphous phases tend to transform into the more stable crystalline phases with the heat supply from the final fracture, which may explain the nanocrystallization for the Sr1 BMG after the mechanical tests. It is noticed that the amount of nanocrystallites for the sample failed under corrosion fatigue test in PBS is less than that for the sample failed under fatigue test in air, which may be ascribed to the better thermal-conduction capability of water than air and the heat was easily transferred to the water.

\section{Discussion}

\subsection{Corrosion fatigue behavior of $\operatorname{Sr} 1 B M G$}

In the present work, Sr1 BMG exhibited the shorter fatigue life under the fatigue tests in PBS than that in air at the same applied stress, and the fatigue strength in PBS was lower than that in air. This decrease in fatigue resistance could be mainly ascribed to the corrosion and the cyclic loading. Sr1 BMG samples went through the peeling-off fractures before the final fragmented fracture, and each fracture started with a crack initiation. For the fatigue tests in air, stress concentration was prone to occur at weak spots including scratches, dents and machining marks on the sample surface, and the inside inhomogeneity like shrinkage voids, pores and inclusions [27, 
28]. When the stress intensity factor reached the threshold, a crack would be initiated [27]. As for the corrosion fatigue situation, it has been reported that stress concentration was apt to occur at corrosion pits and corroded areas, making them ideal sites for crack initiation $[4,15]$. Pitting corrosion is the typical corrosion mode for magnesium alloys, especially in chloride-ion-containing solution like PBS $[3,5]$. For the Sr1 BMG during static immersion, pitting corrosion occurred first, then the corrosion resistance was enhanced by the gradually formed protective surface film, making the alloy degrade at a low and stable rate [9]. But the $\operatorname{Mg}(\mathrm{OH})_{2}$, which was the major component of the protective surface film [9], would slowly react with chloride ions to become soluble $\mathrm{MgCl}_{2}[3,5]$, leaving localized defects on the surface film. While under the corrosion fatigue circumstances, the transition of $\mathrm{Mg}(\mathrm{OH})_{2}$ to $\mathrm{MgCl}_{2}$ could be accelerated, since magnesium alloys were found to be susceptible to stress-corrosion cracking [29], and the corrosion rates could be considerably accelerated in the cyclic loading condition [4]. Additionally, the repeated elastic deformation during the cyclic loading would break the protective surface film. The joint actions of the accelerated corrosion and the repeated deformation weakened the protectiveness of the surface film and exposed the underlying metal directly to the solution. Thus, galvanic corrosion could occur with the surface film acting as the cathode and the bare metal acting as the anode [15]. Crevice corrosion might also happen, if the solution could enter the interspace between the metal and surface layer [30]. Both corrosion processes eased the formation of pits and made the alloy less corrosion-resistant. With the stress concentrating at the pits and the pits growing, cracks initiated when the stress intensity factor reached the critical value [4, 27], and evolved into the peeling-off fractures and the final fragmented fracture afterwards. Therefore, Sr1 BMG exhibited an inferior fatigue resistance in PBS to that in air. 
As abovementioned, cracks initiated from stress-concentration sites, and evolved into the peeling-off fractures. A few regional peeling-off fractures contributed to the first major peeling-off fracture. For the same batch of samples, the one enduring a lower applied cyclic stress would need a longer time for the crack initiation, suggesting that for the samples tested in air, the number of cycles to the first major peeling-off fracture increased with decreasing the applied stress. For the samples tested in PBS, the initiation of crack was easier than that in air, because the corrosion offered many corrosion pits and corroded areas, which were considerably inclined to be stress concentrators. Thus, compared with the sample tested in air, the one tested at the same applied stress in PBS would encounter the first major peeling-off fracture with a smaller number of cycles. During the static immersion in PBS, Sr1 BMG would be protected by a surface oxidation film gradually formed in a certain period, which worked as the shell of the inner active metal and slowed down the corrosion rate to a low and stable value [9]. Under the corrosion fatigue circumstances, the time-dependent formation of the protective surface film would help retard the corrosion processes and reduce the amount of corrosion pits. Meanwhile, with the decrease in applied stress, the accelerated corrosion and the repeated deformation, which resulted from the cyclic loading, would diminish. Thus, the surface film formation and the decreased applied stress would be responsible for the change in the variation of the number of cycles to the first major peeling-off fracture for the samples tested in PBS (Fig. 8). After the occurrence of the first major peeling-off fracture, the remaining cross-sectional area of the sample decreased, and the actual applied stress became higher than the set value, because the set stress was the nominal value of the applied load divided by the initial cross-sectional area. Since the fatigue life of $\mathrm{Sr} 1$ BMG was very sensitive to the applied stress, the sample suffered the first major 
peeling-off fracture would confront the final fragmented fracture in a much shorter period, compared with the time that the sample needed to encounter the first major peeling-off fracture. Therefore, for the samples tested in PBS, the plot of the applied stress versus the number of cycles to failure shares an analogical variation with the curve of the applied stress versus the number of cycles to the first major peeling-off fracture.

4.2 Comparison of fatigue properties among the $\mathrm{Mg}$-Zn-Ca-Sr BMG and some metallic biomaterials

The fatigue strengths at $10^{7}$ cycles tested in air and in corrosion medium of the Sr1 BMG and some as-reported crystalline Mg alloys for biomedical applications, including AZ61 [31], AZ80-T5 [32], AZ31 [33] and WE43 [4], are displayed in Fig. 10. Sr1 BMG exhibits a much higher fatigue strength in air $(370 \mathrm{MPa})$ than those of the listed crystalline Mg alloys (110-150 MPa), demonstrating the intrinsic advantage in the mechanical strength of the BMG due to the amorphous structure [6]. A large decrease in fatigue strength in corrosion medium, compared with the fatigue strength in air, is observed for the $\mathrm{Mg}$ alloys, suggesting their susceptibility to corrosion fatigue. Sr1 BMG possesses the corrosion fatigue strength of $150 \mathrm{MPa}$, which is much superior to those ranging from 30 to $80 \mathrm{MPa}$ for the crystalline $\mathrm{Mg}$ alloys.

Young's modulus is an important mechanical property that should be considered for the application of a biomaterial, since the use of a material with a much higher Young's modulus than that of bone could introduce severe stress-shielding effects, leading to bone absorption and loosening or failure of implants [34]. Figure 11 presents the data of the fatigue strength in a simulated physiological environment versus Young's modulus of the Sr1 BMG and some commonly investigated metallic biomaterials, as well as bone $[4,9,31-33,35-41]$. It can be seen that the crystalline 
Mg alloys possess lower fatigue strength than those of the bio-inert Ti alloys, stainless steels and Co-Cr alloys, but they own merits of lower Young's modulus and no need of implant-removal surgery due to the biodegradability. Compared with the crystalline Mg alloys, Sr1 BMG exhibits comparable Young's modulus, but much higher fatigue strength, which parallel to that of stainless steels.

It is known that a qualified biodegradable biomaterial for orthopedic implantation should perform properly for at least 3 months [2]. To fulfill this purpose, biodegradable biomaterials should exhibit fatigue strength which is at least higher than that of human bone for the entire duration of healing. As reported by Taylor [35], for human bone, typical strains are 1200-1500 microstrains for normal walking, and 2000-3000 microstrains for strenuous activities (e.g., running) and accidents (e.g., stumbling), which equate to 20.4-25.5 and 34-51 MPa, respectively, assuming the Young's modulus is $17 \mathrm{GPa}$. Considering the annual cycles of repetition for normal walking is about 2 million times [35], the material will bear at least $5 \times 10^{5}$ cycles. For Sr1 BMG with a fatigue endurance limit of $150 \mathrm{MPa}$, the anticipated fatigue strength for $5 \times 10^{5}$ cycles is $215 \mathrm{MPa}$, which is much higher than the bone fatigue strength (23-30 MPa) and the physiological strengths of 25.5 and $51 \mathrm{MPa}$ [35]. Thus, $\mathrm{Mg}_{66} \mathrm{Zn}_{30} \mathrm{Ca}_{3} \mathrm{Sr}_{1}$ BMG meets the qualification of fatigue property for biodegradable biomaterials.

\section{Conclusions}

In the present work, the fatigue behaviors of $\mathrm{Mg}_{66} \mathrm{Zn}_{30} \mathrm{Ca}_{3} \mathrm{Sr}_{1}$ BMG tested in air and in a simulated physiological environment were studied. Based on the results and discussion above, the following conclusions were reached.

(1) The $\mathrm{Mg}_{66} \mathrm{Zn}_{30} \mathrm{Ca}_{3} \mathrm{Sr}_{1}$ BMG exhibited fatigue strengths of 370 and $150 \mathrm{MPa}$ in air and in the simulated physiological environment, respectively. The corrosion in the 


\section{References}

[1] F. Witte, The history of biodegradable magnesium implants: A review, Acta Biomater. 6 (2010) 1680-1692.

[2] M.P. Staiger, A.M. Pietak, J. Huadmai, G. Dias, Magnesium and its alloys as orthopedic biomaterials: A review, Biomaterials 27 (2006) 1728-1734.

[3] Y.F. Zheng, X.N. Gu, F. Witte, Biodegradable metals, Mater. Sci. Eng., R 77 (2014) $1-34$.

[4] X.N. Gu, W.R. Zhou, Y.F. Zheng, Y. Cheng, S.C. Wei, S.P. Zhong, T.F. Xi, L.J. Chen, Corrosion fatigue behaviors of two biomedical Mg alloys - AZ91D and WE43 - In simulated body fluid, Acta Biomater. 6 (2010) 4605-4613.

[5] Y. Xin, T. Hu, P.K. Chu, In vitro studies of biomedical magnesium alloys in a simulated physiological environment: A review, Acta Biomater. 7 (2011) 1452-1459.

[6] W.H. Wang, C. Dong, C.H. Shek, Bulk metallic glasses, Mater. Sci. Eng. R-Rep. 44 (2004) 45-89.

[7] B. Zberg, P.J. Uggowitzer, J.F. Loffler, MgZnCa glasses without clinically observable hydrogen evolution for biodegradable implants, Nat. Mater. 8 (2009) 887-891.

[8] X.N. Gu, Y.F. Zheng, S.P. Zhong, T.F. Xi, J.Q. Wang, W.H. Wang, Corrosion of, and cellular responses to $\mathrm{Mg}-\mathrm{Zn}-\mathrm{Ca}$ bulk metallic glasses, Biomaterials 31 (2010) 1093-1103.

[9] H.F. Li, S.J. Pang, Y. Liu, L.L. Sun, P.K. Liaw, T. Zhang, Biodegradable $\mathrm{Mg}-\mathrm{Zn}-\mathrm{Ca}-\mathrm{Sr}$ bulk metallic glasses with enhanced corrosion performance for biomedical applications, Mater. Des. 67 (2015) 9-19.

[10] H.F. Li, S.J. Pang, Y. Liu, P.K. Liaw, T. Zhang, In vitro investigation of $\mathrm{Mg}-\mathrm{Zn}-\mathrm{Ca}-\mathrm{Ag}$ bulk metallic glasses for biomedical applications, J. Non-Cryst. Solids 427 (2015) 134-138.

[11] F.X. Qin, G.Q. Xie, Z. Dan, S.L. Zhu, I. Seki, Corrosion behavior and mechanical properties of Mg-Zn-Ca amorphous alloys, Intermetallics 42 (2013) 9-13. [12] X.L. Zhang, G. Chen, T. Bauer, Mg-based bulk metallic glass composite with high bio-corrosion resistance and excellent mechanical properties, Intermetallics 29 (2012) 56-60.

[13] B.D. Ratner, A.S. Hoffman, F.J. Schoen, J.E. Lemons, Biomaterials science: an introduction to materials in medicine, Academic press, Waltham, Massachusetts, USA, 2004. 
[14] C.R.F. Azevedo, Failure analysis of a commercially pure titanium plate for

[15] L. Huang, G. Wang, D. Qiao, P.K. Liaw, S. Pang, J. Wang, T. Zhang, Corrosion-fatigue study of a Zr-based bulk-metallic glass in a physiologically relevant environment, J. Alloy. Compd. 504 (2010) S159-S162.

[16] J.Q. Li, L. Wang, H.W. Cheng, H.F. Zhang, Z.Q. Hu, H.N. Cai, Fracture surface morphology of Mg-based bulk metallic glass and composite during quasi-static and dynamic compressive deformation, J. Alloy. Compd. 478 (2009) 827-830.

[17] M. Stoica, J. Eckert, S. Roth, Z.F. Zhang, L. Schultz, W.H. Wang, Mechanical behavior of Fe65.5Cr4Mo4Ga4P12C5B5.5 bulk metallic glass, Intermetallics 13 (2005) 764-769.

[18] G. Wang, P.K. Liaw, O.N. Senkov, D.B. Miracle, M.L. Morrison, Mechanical and fatigue behavior of Ca65Mg15Zn20 bulk-metallic glass, Adv. Eng. Mater. 11 (2009) 27-34.

[19] C.M. Zhang, X. Hui, Z.G. Li, G.L. Chen, Improving the strength and the toughness of $\mathrm{Mg}-\mathrm{Cu}-(\mathrm{Y}, \mathrm{Gd})$ bulk metallic glass by minor addition of $\mathrm{Nb}$, J. Alloy. Compd. 467 (2009) 241-245.

[20] J. Eckert, J. Das, S. Pauly, C. Duhamel, Mechanical properties of bulk metallic glasses and composites, J. Mater. Res. 22 (2007) 285-301.

[21] H. Peng, S.S. Li, Y.P. Qi, T.Y. Huang, Mg-Ni-Gd-Ag bulk metallic glass with improved glass-forming ability and mechanical properties, Intermetallics 19 (2011) 829-832.

[22] M. Freels, G.Y. Wang, W. Zhang, P.K. Liaw, A. Inoue, Cyclic compression behavior of a Cu-Zr-Al-Ag bulk metallic glass, Intermetallics 19 (2011) 1174-1183. [23] J. Tan, F.S. Pan, Y. Zhang, B.A. Sun, J. He, N. Zheng, M. Stoica, U. Kuehn, J. Eckert, Formation of $\mathrm{Zr}$-Co-Al bulk metallic glasses with high strength and large plasticity, Intermetallics 31 (2012) 282-286.

[24] T. Zhang, H. Men, Plastic deformability and precipitation of nanocrystallites during compression for a Cu-Zr-Ti-Sn bulk metallic glass, J. Alloy. Compd. 434 (2007) $10-12$.

[25] Y.D. Sun, Q.R. Chen, G.Z. Li, Enhanced glass forming ability and plasticity of Mg-based bulk metallic glass by minor addition of Cd, J. Alloy. Compd. 584 (2014) 273-278.

[26] G.Y. Wang, P.K. Liaw, W.H. Peter, B. Yang, Y. Yokoyama, M.L. Benson, B.A. 
Green, M.J. Kirkham, S.A. White, T.A. Saleh, R.L. McDaniels, R.V. Steward, R.A. Intermetallics 12 (2004) 885-892.

[27] S. Suresh, Fatigue of Materials, Second ed, Cambridge University Press, Cambridge, England, 1998.

[28] Y. Yue, R. Wang, D.Q. Ma, J.F. Tian, X.Y. Zhang, Q. Jing, M.Z. Ma, R.P. Liu, Fatigue behavior of a Zr-based bulk metallic glass under uniaxial tension-tension and three-point bending loading mode, Intermetallics 60 (2015) 86-91.

[29] B.S. Padekar, R.K.S. Raman, V.S. Raja, L. Paul, Stress corrosion cracking of a recent rare-earth containing magnesium alloy, EV31A, and a common Al-containing alloy, AZ91E, Corros. Sci. 71 (2013) 1-9.

[30] Z.B. Sajuri, Y. Miyashita, Y. Mutoh, Effects of humidity and temperature on the fatigue behaviour of an extruded AZ61 magnesium alloy, Fatigue Fract. Eng. M. 28 (2005) 373-379.

[31] A. Němcová, P. Skeldon, G.E. Thompson, S. Morse, J. Č́ížek, B. Pacal, Influence of plasma electrolytic oxidation on fatigue performance of AZ61 magnesium alloy, Corros. Sci. 82 (2014) 58-66.

[32] M.S. Bhuiyan, Y. Mutoh, T. Murai, S. Iwakami, Corrosion fatigue behavior of extruded magnesium alloy AZ80-T5 in a 5\% NaCl environment, Eng. Fract. Mech. 77 (2010) 1567-1576.

[33] Z.Y. Nan, S. Ishihara, T. Goshima, Corrosion fatigue behavior of extruded magnesium alloy AZ31 in sodium chloride solution, Int. J. Fatigue 30 (2008) 1181-1188.

[34] J. Nagels, M. Stokdijk, P.M. Rozing, Stress shielding and bone resorption in shoulder arthroplasty, J. Shoulder Elbow Surg. 12 (2003) 35-39.

[35] D. Taylor, Fatigue of bone and bones: an analysis based on stressed volume, J. Orthop. Res. 16 (1998) 163-169.

[36] M. Long, H.J. Rack, Titanium alloys in total joint replacement - a materials science perspective, Biomaterials 19 (1998) 1621-1639.

[37] M. Niinomi, Fatigue characteristics of metallic biomaterials, Int. J. Fatigue 29 (2007) 992-1000.

[38] Q. Chen, G.A. Thouas, Metallic implant biomaterials, Mater. Sci. Eng., R 87 (2015) 1-57.

[39] Y. Okazaki, S. Rao, Y. Ito, T. Tateishi, Corrosion resistance, mechanical 
properties, corrosion fatigue strength and cytocompatibility of new Ti alloys without $\mathrm{Al}$ and V, Biomaterials 19 (1998) 1197-1215.

[40] N. Maruyama, D. Mori, S. Hiromoto, K. Kanazawa, M. Nakamura, Fatigue strength of 316L-type stainless steel in simulated body fluids, Corros. Sci. 53 (2011) 2222-2227.

[41] M. Niinomi, T. Kobayashi, O. Toriyama, N. Kawakami, Y. Ishida, Y. Matsuyama, Fracture characteristics, microstructure, and tissue reaction of $\mathrm{Ti}-5 \mathrm{Al}-2.5 \mathrm{Fe}$ for orthopedic surgery, Metall. Mater. Trans. A-Phys. Metall. Mater. Sci. 27 (1996) 3925-3935. 


\section{Figure captions}

Fig. 1. Stress-life curves for the compression-compression fatigue tests in air and in PBS of $\mathrm{Mg}_{66} \mathrm{Zn}_{30} \mathrm{Ca}_{3} \mathrm{Sr}_{1} \mathrm{BMG}$.

Fig. 2. SEM images showing the fracture morphologies of the Mg-Zn-Ca-Sr BMG failed under compression test: (a) overview of the fracture fragments; (b) conchoidal fracture features; (c) rock-layer patterns; (d) vein-like patterns [frame (i)], river-like patterns [frame (ii)], and local melting (arrows).

Fig. 3. SEM images showing the fracture morphologies of the Mg-Zn-Ca-Sr BMG fatigue-failed in air at a $\sigma_{\max }$ of $425 \mathrm{MPa}$ : (a) conchoidal fracture features, pore and microcrack; (b) rock-layer patterns; (c) vein-like and river-like patterns.

Fig. 4. SEM images showing the fracture morphologies of the Mg-Zn-Ca-Sr BMG fatigue-failed in PBS at a $\sigma_{\max }$ of $250 \mathrm{MPa}$ : (a) conchoidal fracture features, a surface film and nano-sized corrosion pits; (b) rock-layer patterns; (c) vein-like and river-like patterns; (d) large-sized corrosion pits and microcracks after cleaning the corrosion products.

Fig. 5. A schematic illustration for the configuration of the as-cast Mg-Zn-Ca-Sr BMG and the BMG after the first major peeling-off fracture. The dotted lines indicate the initial sample geometry.

Fig. 6. SEM images showing the fracture morphologies of the Mg-Zn-Ca-Sr BMG after a controlled fatigue test in air at a $\sigma_{\max }$ of $425 \mathrm{MPa}$ : (a) overview; (b) conchoidal fracture features and several small-regional peeling-off fractures (frames); (c) a boundary between smooth areas and river-like patterns; (d) flaws. Figures (b-d) are the high-magnification images for region (i), (ii) and (iii) in Fig. a, respectively.

Fig. 7. SEM images showing the fracture morphologies of the Mg-Zn-Ca-Sr BMG after a controlled fatigue test in PBS at a $\sigma_{\max }$ of $250 \mathrm{MPa}$ : (a) overview; (b) tear lines, 
corroded areas, and the inset displaying severe corrosion at a corner of the sample; (c) conchoidal fracture features and flaws; (d) pore and microcracks. Figures (b-d) and the inset of Fig. b are the high-magnification images for region (i), (ii), (iii) and (iv) in Fig. a, respectively.

Fig. 8. The applied maximum stress as a function of the number of cycles to the first major peeling-off fracture for the Mg-Zn-Ca-Sr BMG.

Fig. 9. HRTEM images and SAED patterns of the Mg-Zn-Ca-Sr BMG (a) before the mechanical tests, (b) after the compression test, (c) after the fatigue test in air at a $\sigma_{\max }$ of $425 \mathrm{MPa}$, and (d) after the fatigue test in PBS at a $\sigma_{\max }$ of $250 \mathrm{MPa}$.

Fig. 10. Comparison of the fatigue strengths at $10^{7}$ cycles tested in air and in corrosion medium among the $\mathrm{Mg}-\mathrm{Zn}-\mathrm{Ca}-\mathrm{Sr} \mathrm{BMG}$ and some as-reported crystalline $\mathrm{Mg}$ alloys for biomedical applications [4, 31-33]. (For extruded WE43 alloy, axial fatigue with a frequency of $10 \mathrm{~Hz}$ and a stress ratio of -1 was conducted in air and in SBF [4]. For extruded AZ61 alloy, axial fatigue with a frequency of $90 \mathrm{~Hz}$ and a stress ratio of 0 was conducted in air and in $3.5 \mathrm{wt} . \% \mathrm{NaCl}$ solution [31]. For extruded AZ80-T5 alloy, axial fatigue with a frequency of $20 \mathrm{~Hz}$ and a stress ratio of -1 was conducted in air and in a sprayed 5 wt.\% $\mathrm{NaCl}$ solution environment [32]. For extruded AZ31 alloy, cantilever-type rotating bending fatigue with a frequency of $30 \mathrm{~Hz}$ and a stress ratio of -1 was conducted in air and in 3 wt. $\% \mathrm{NaCl}$ solution [33].)

Fig. 11. Comparison of the fatigue strength in a simulated physiological environment and Young's modulus among the Mg-Zn-Ca-Sr BMG and some commonly investigated metallic biomaterials [4, 9, 31-33, 35-41]. 


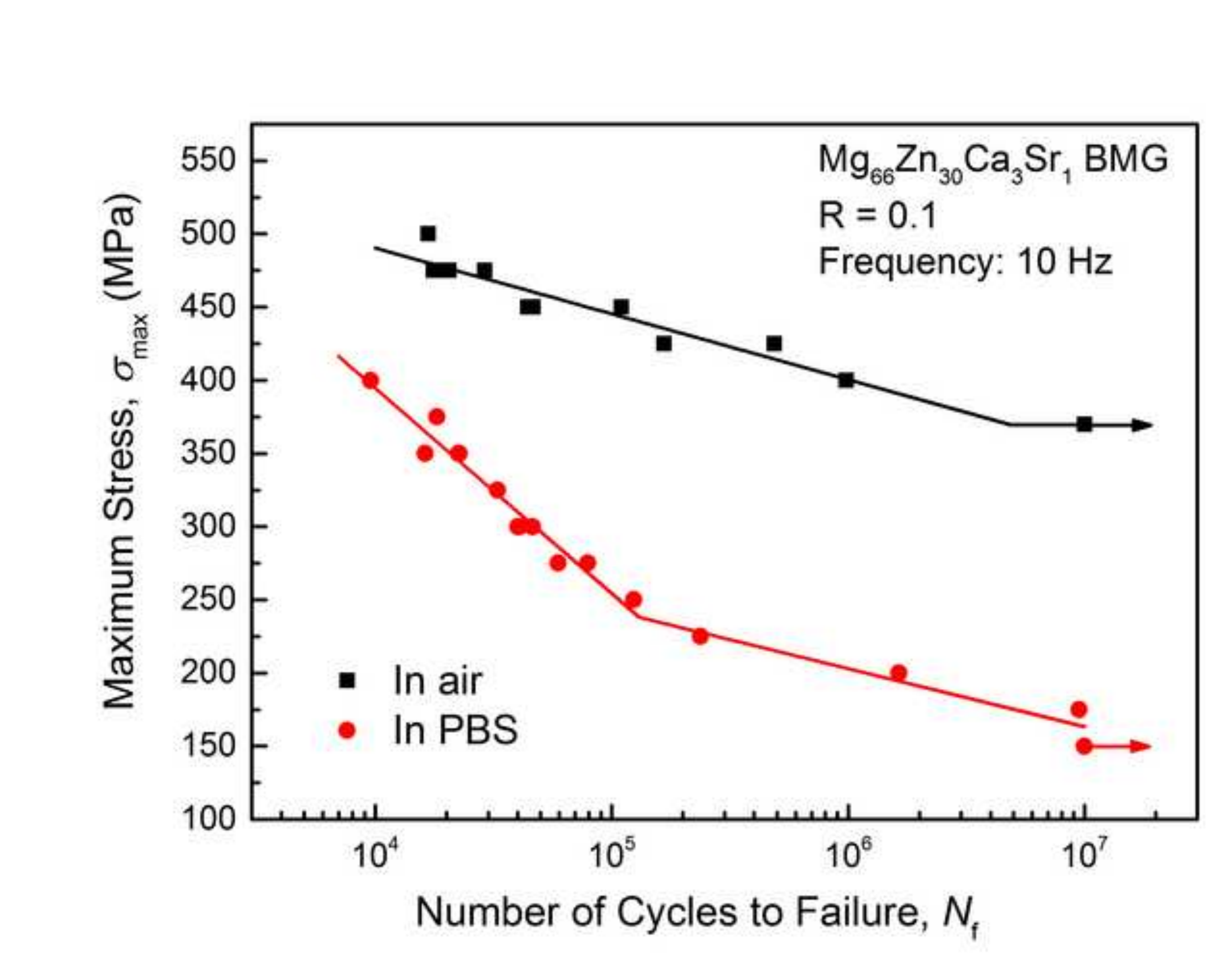

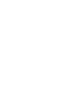




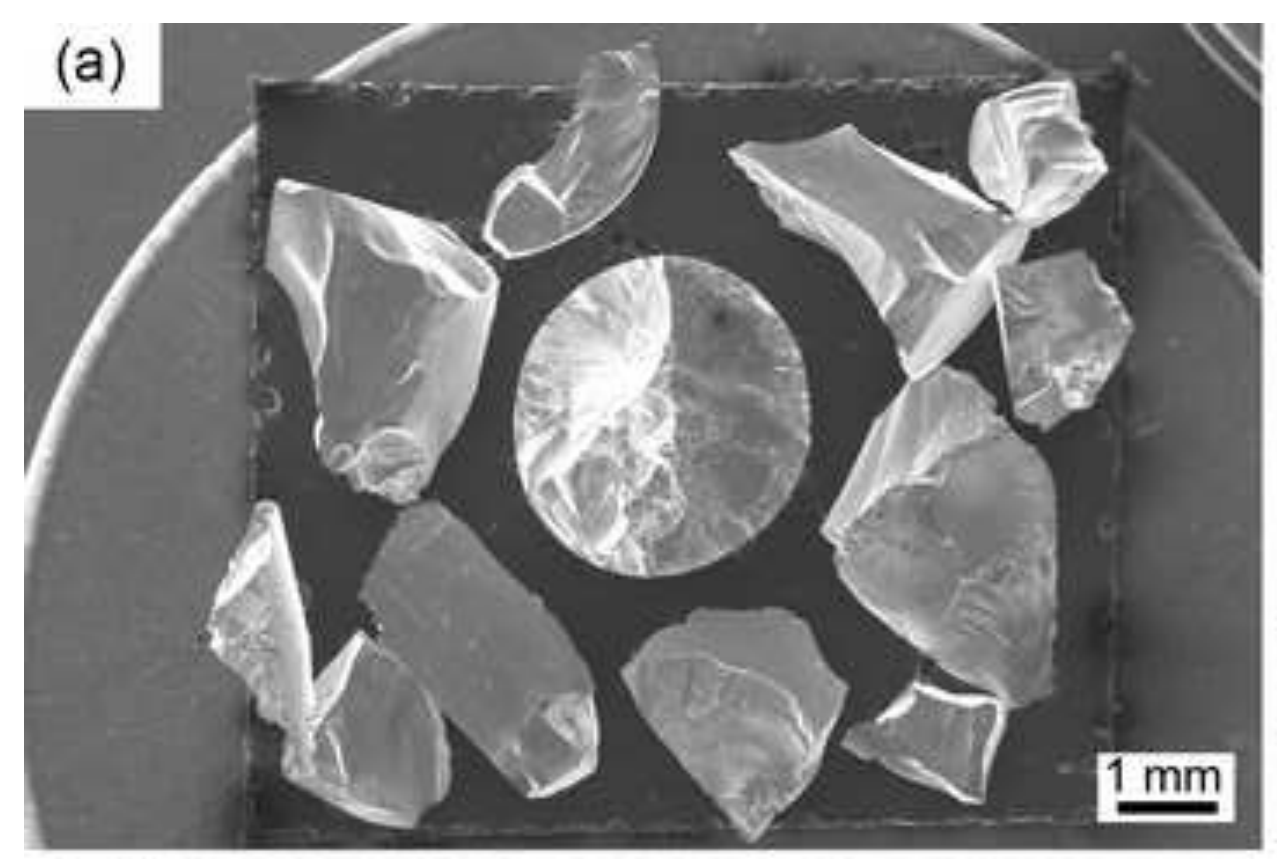

(b)

(c)

Rock-layer patterns
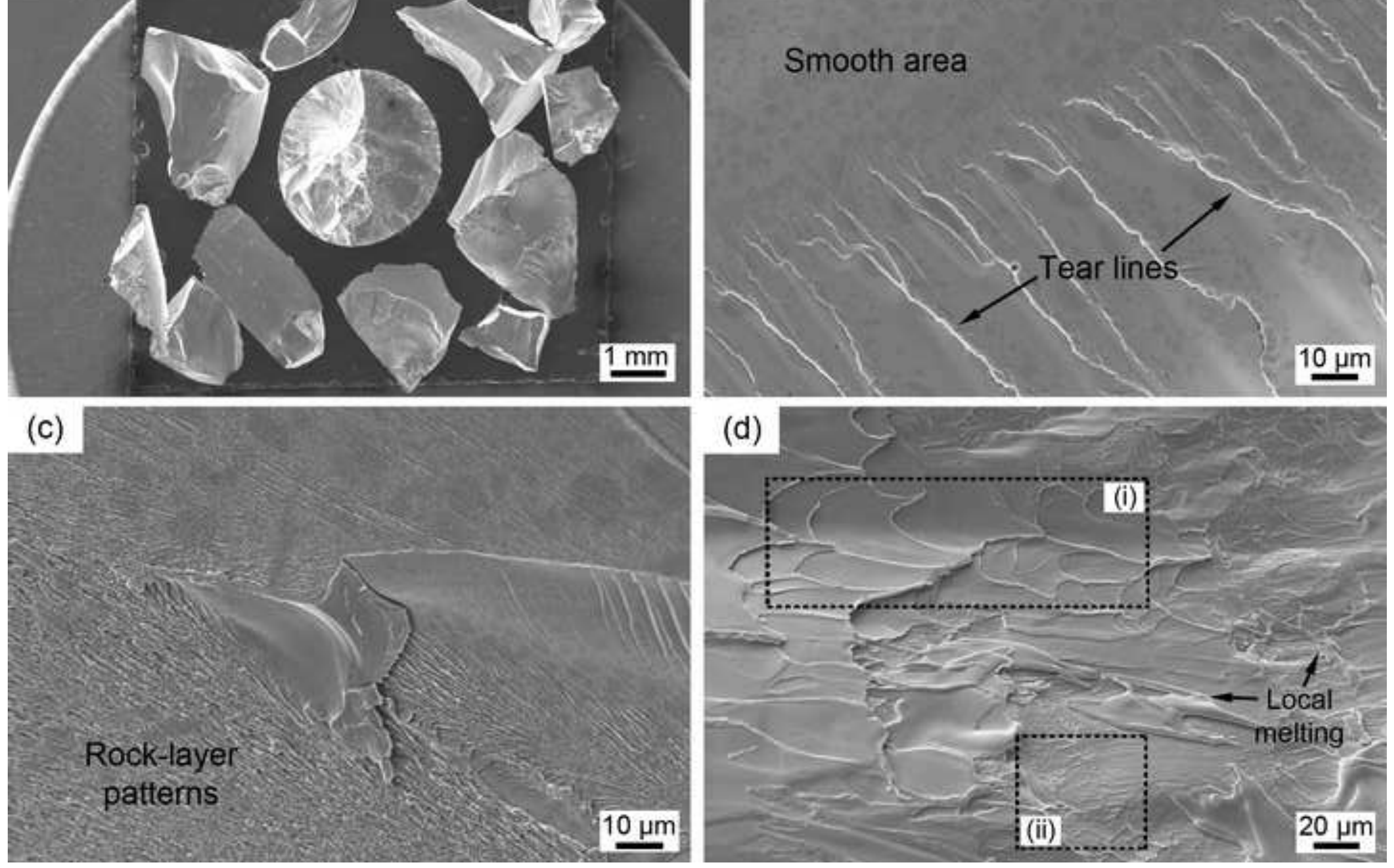
(a)

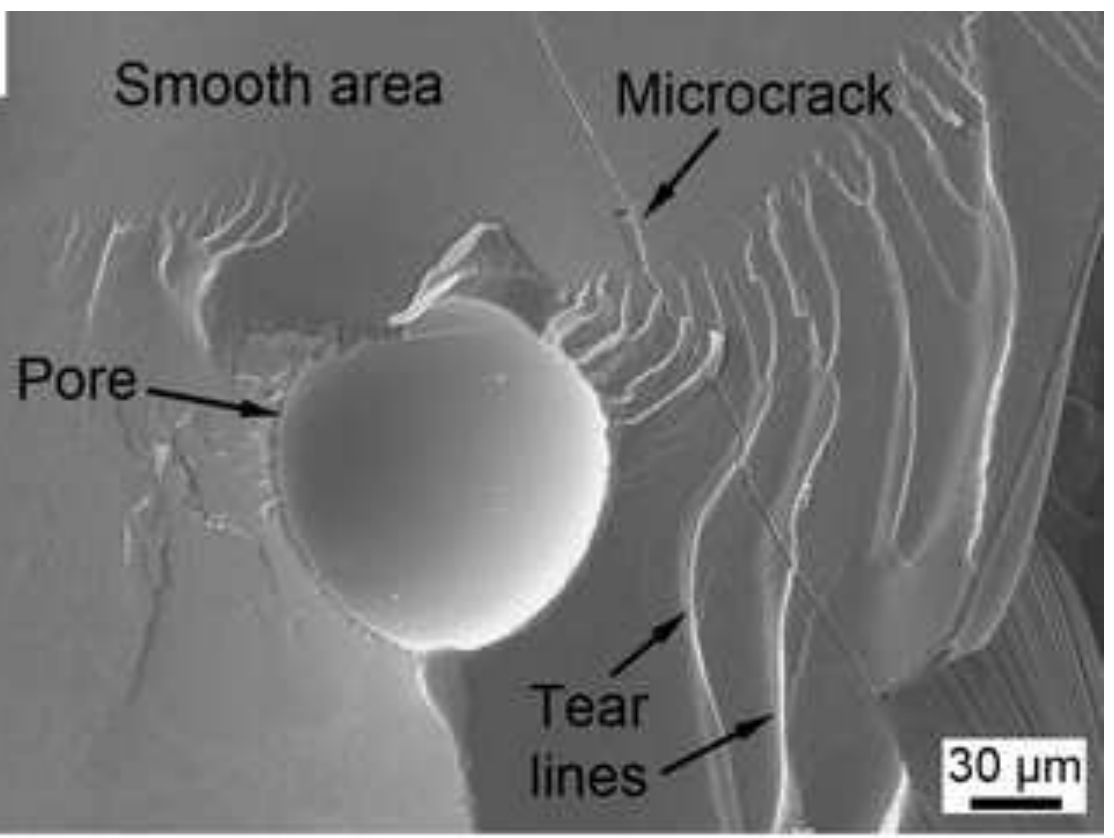

(b)

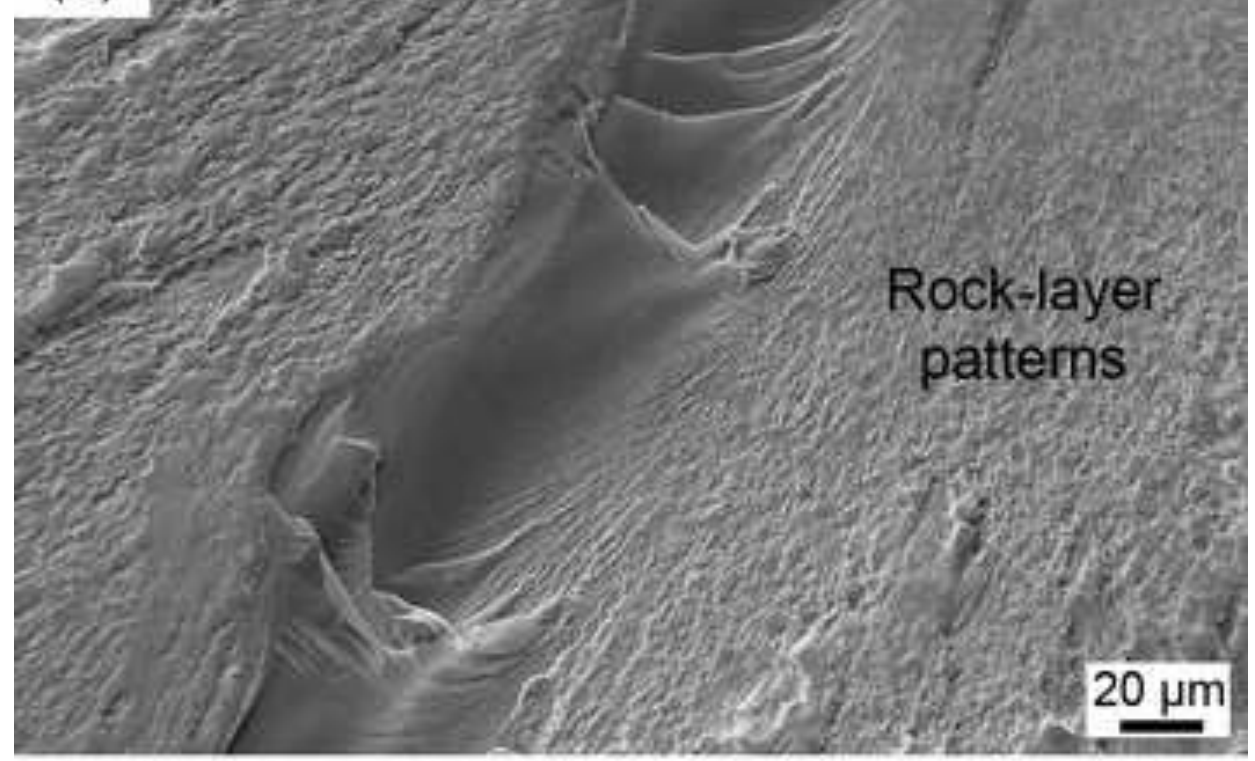

(c)

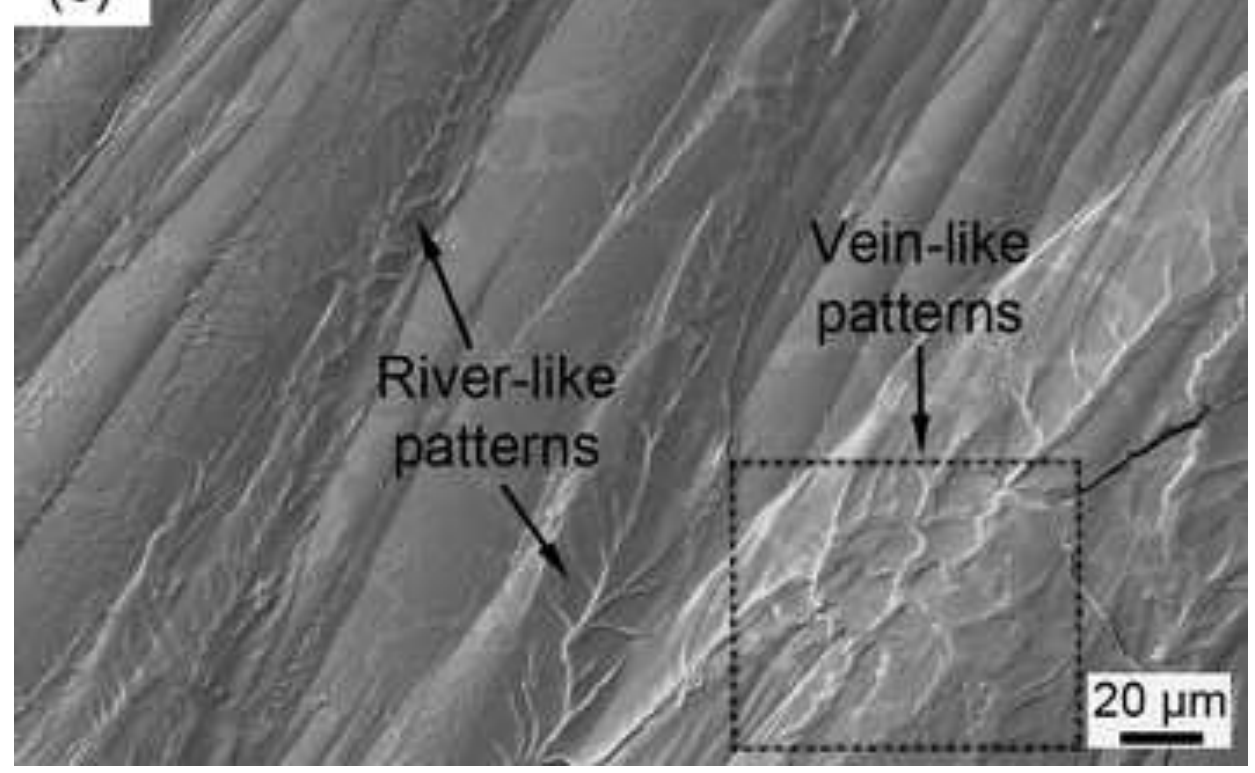


(a)

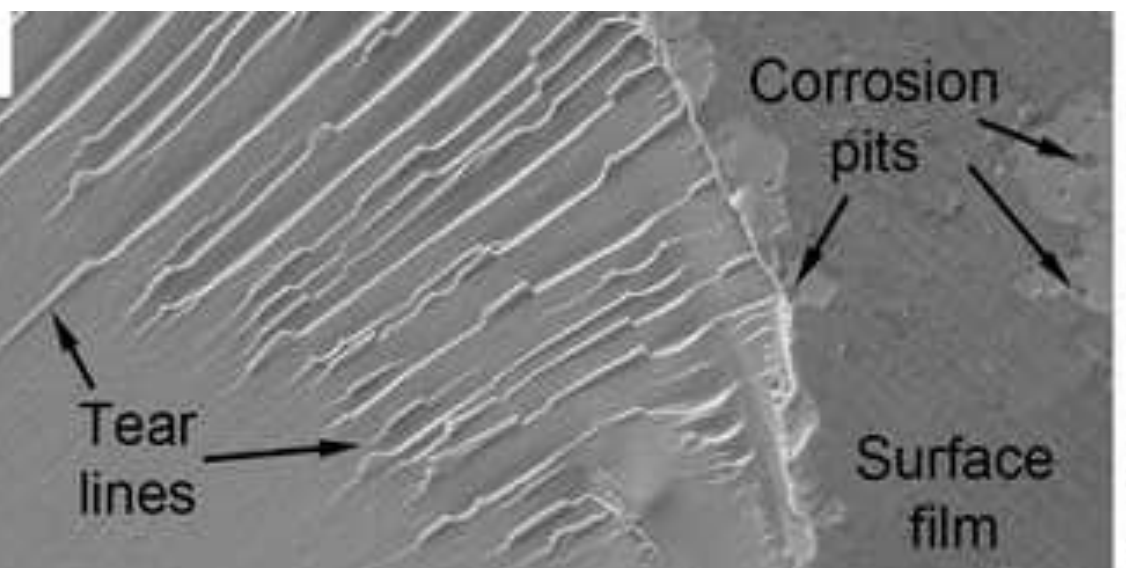

Smooth area

(c)

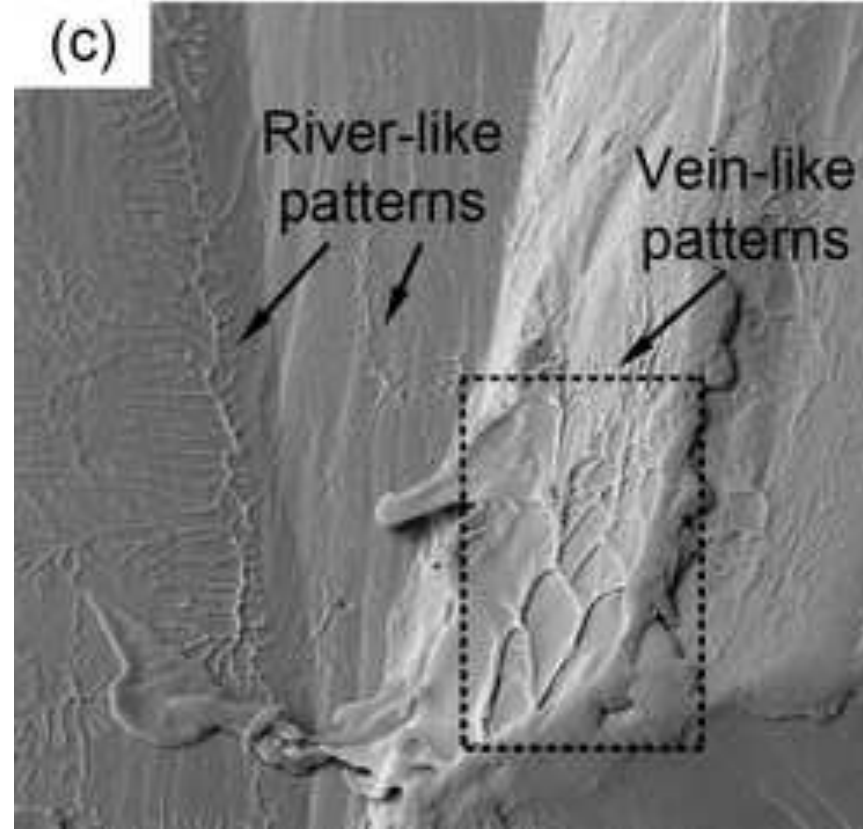

(b)

$10 \mu \mathrm{m}$

(d)

$20 \mu \mathrm{m}$
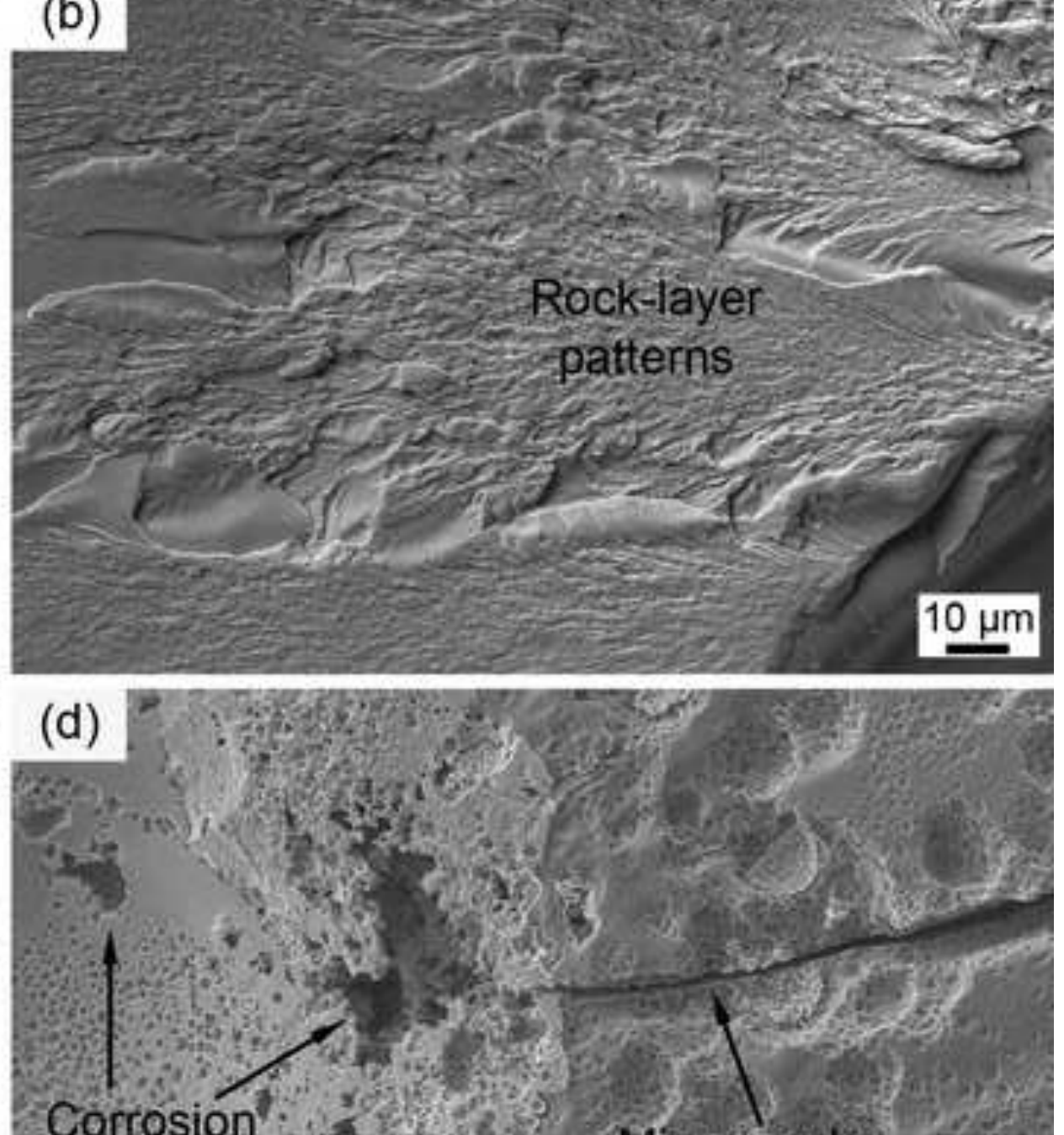
Carrosion, 19 Microcracks.
pits.

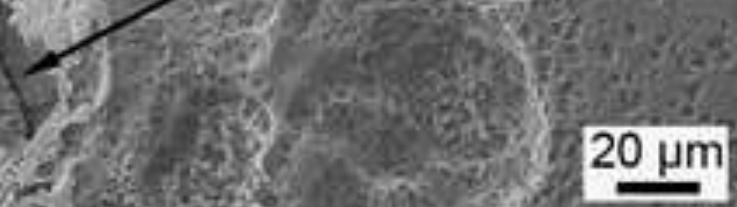


As-cast

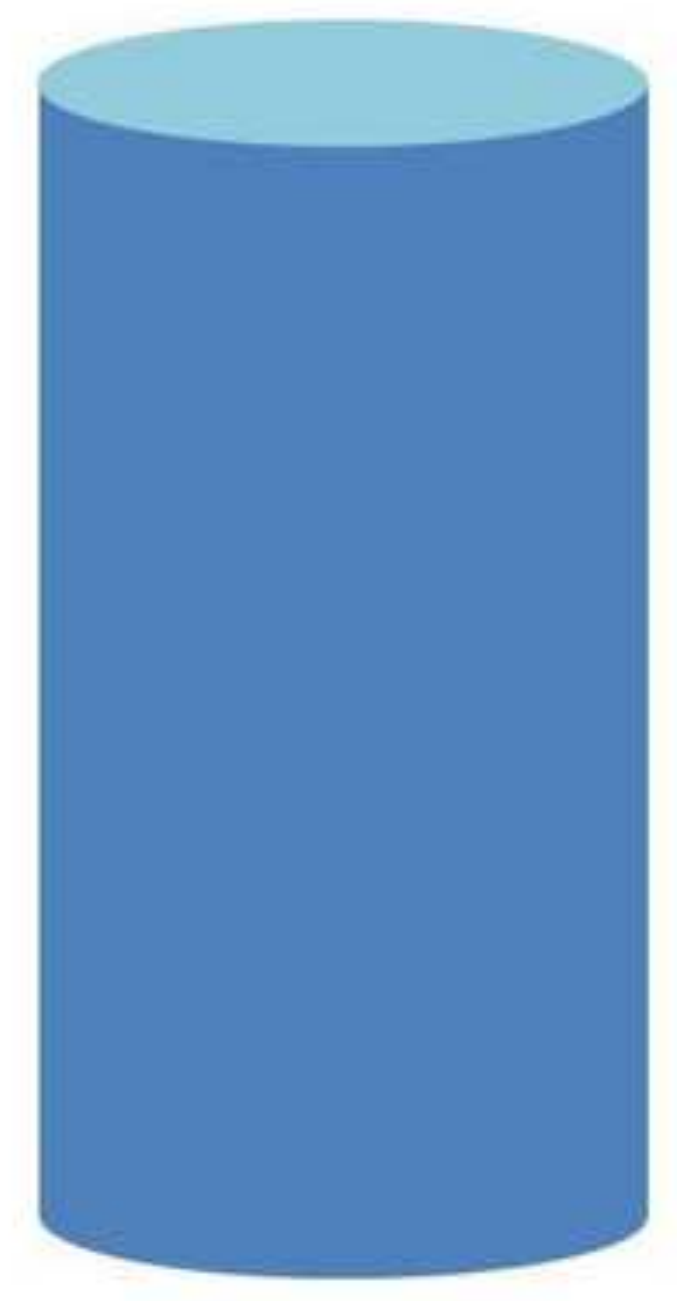

After the first major peeling-off fracture

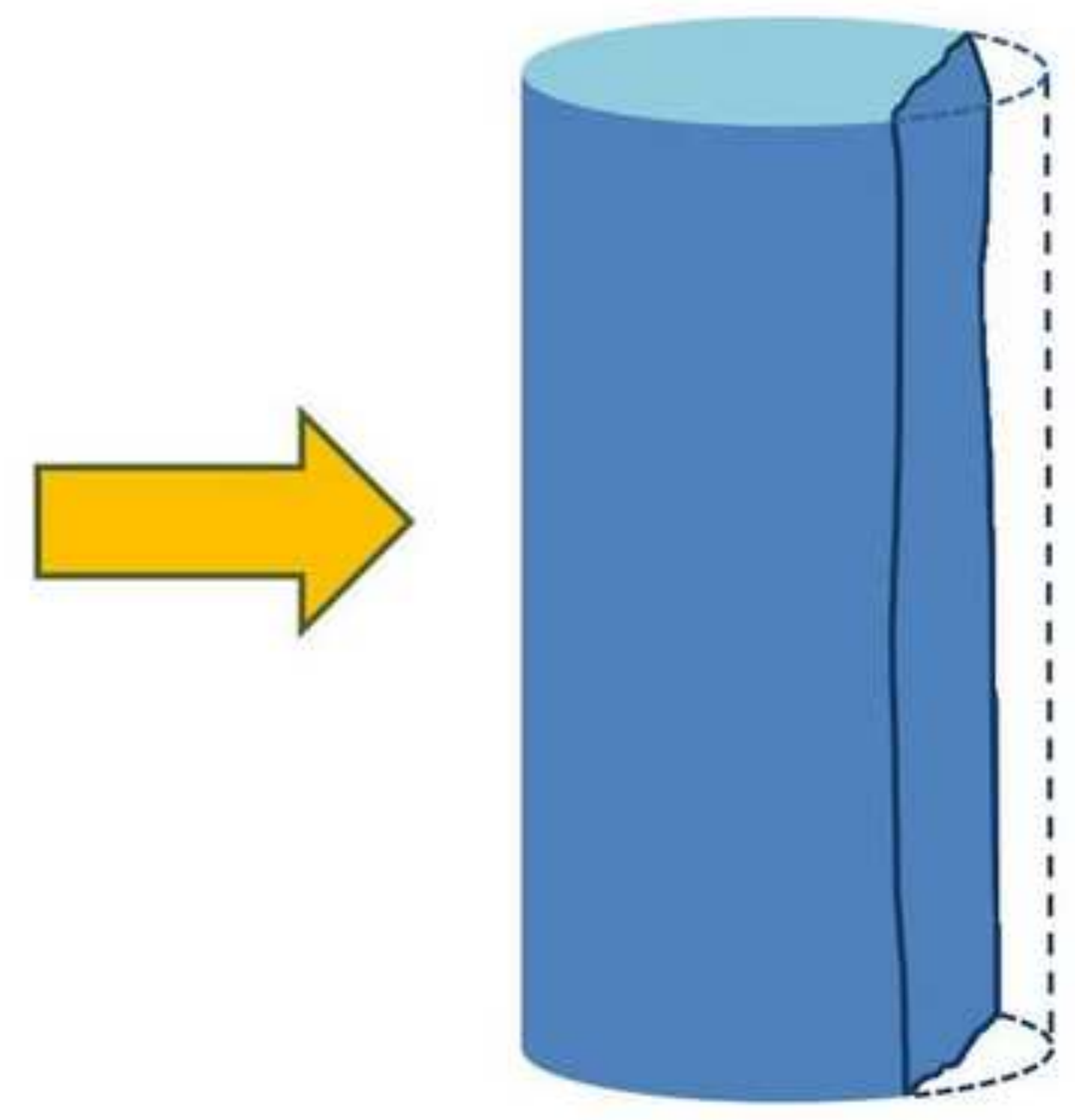


(a)

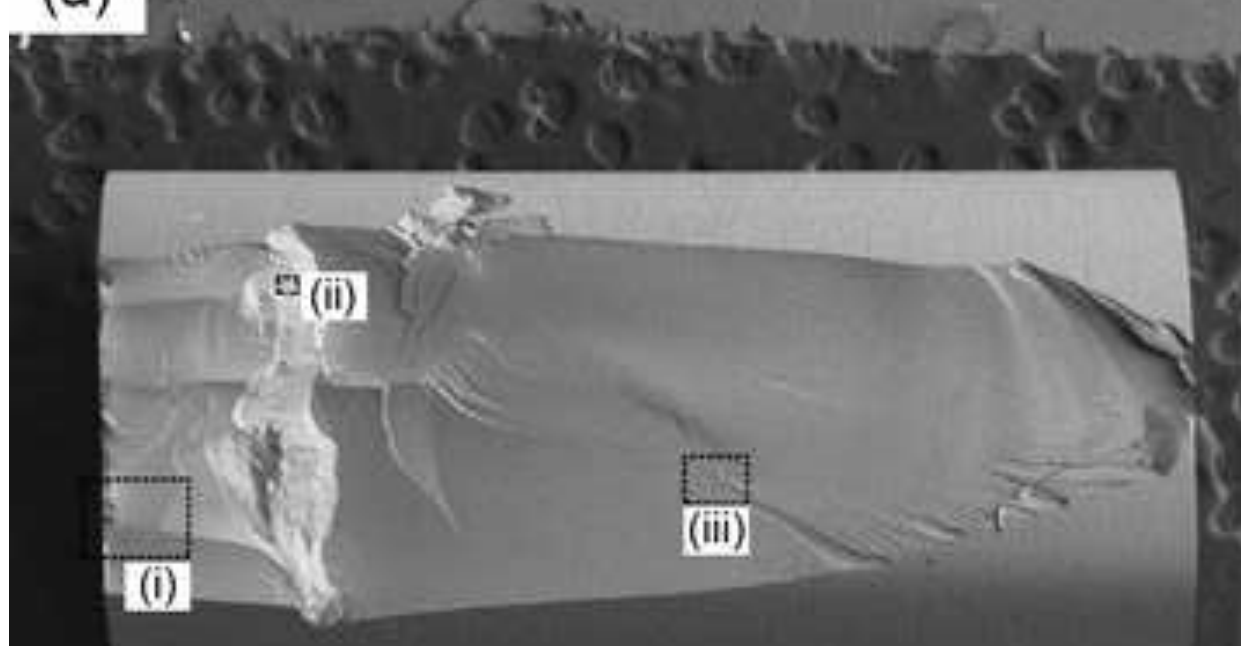

$500 \mu \mathrm{m}$

(c)
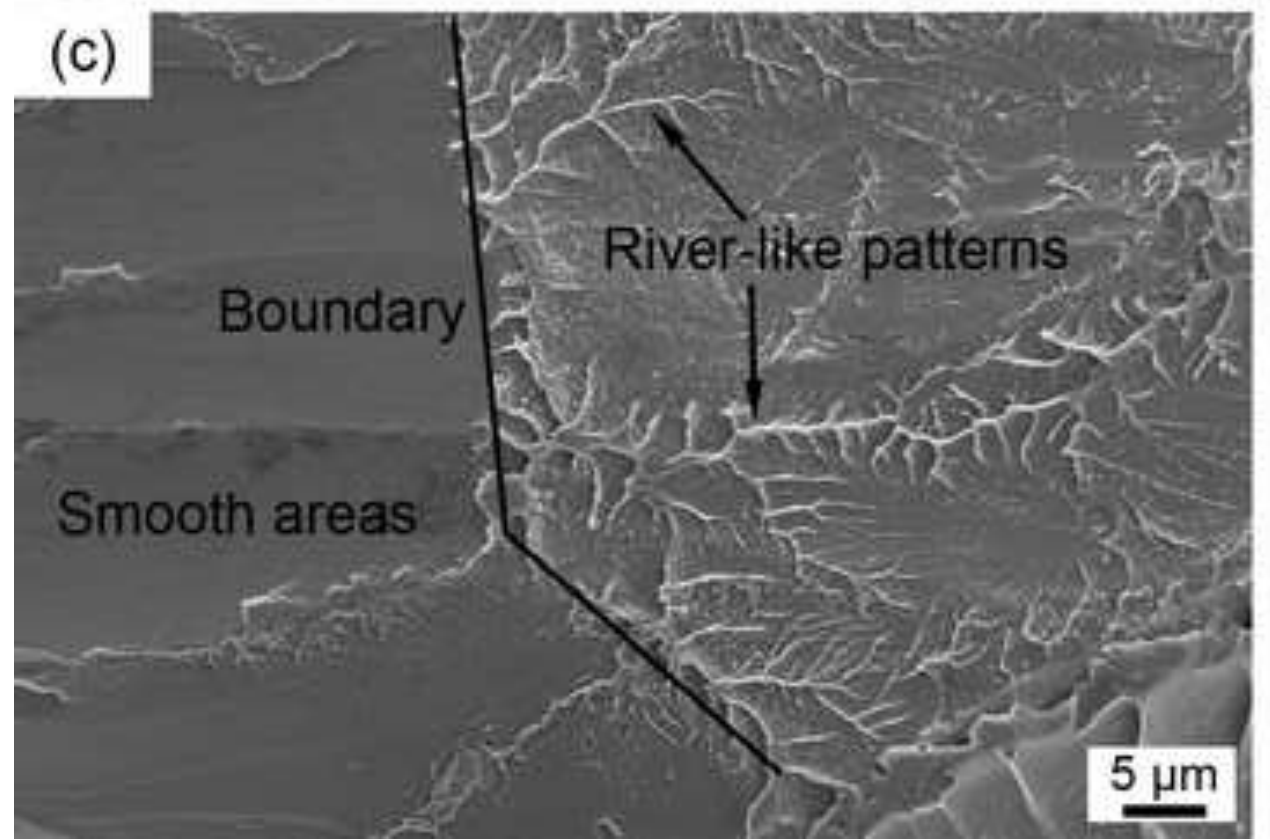

(b)

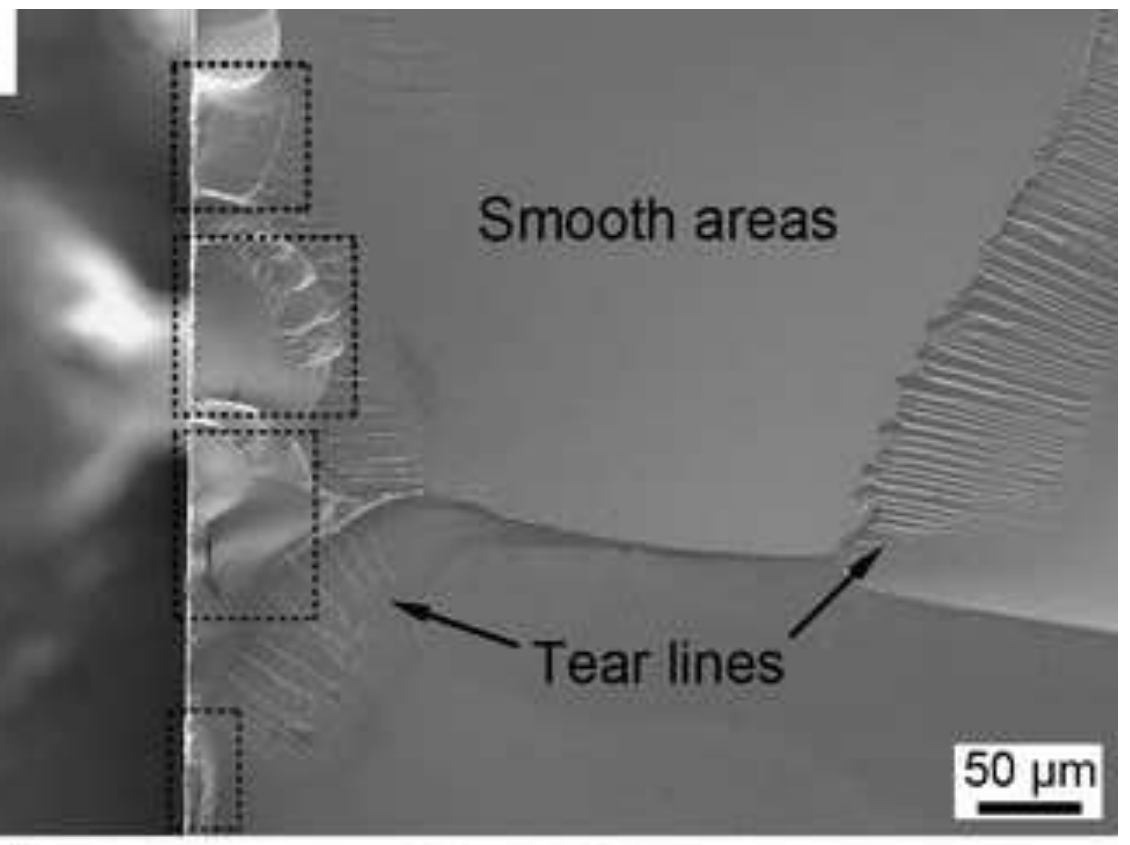

(d)

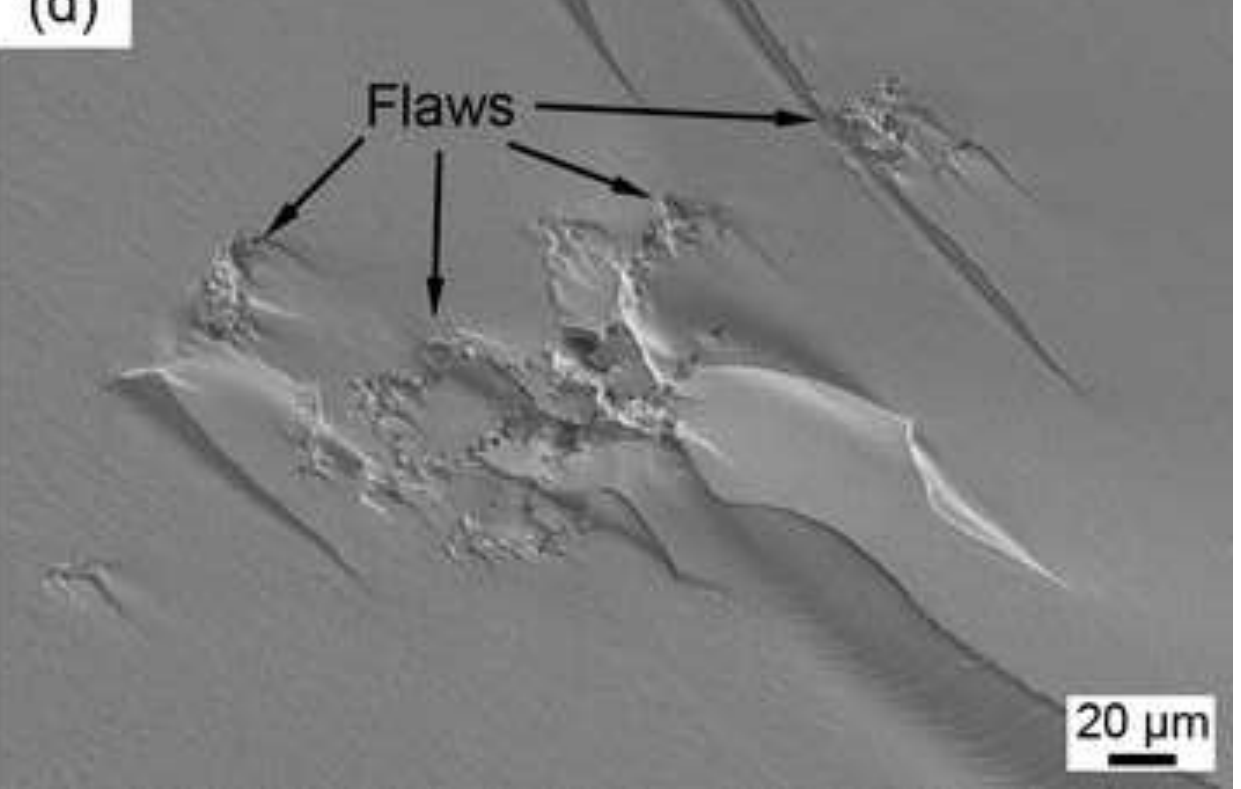


(a)

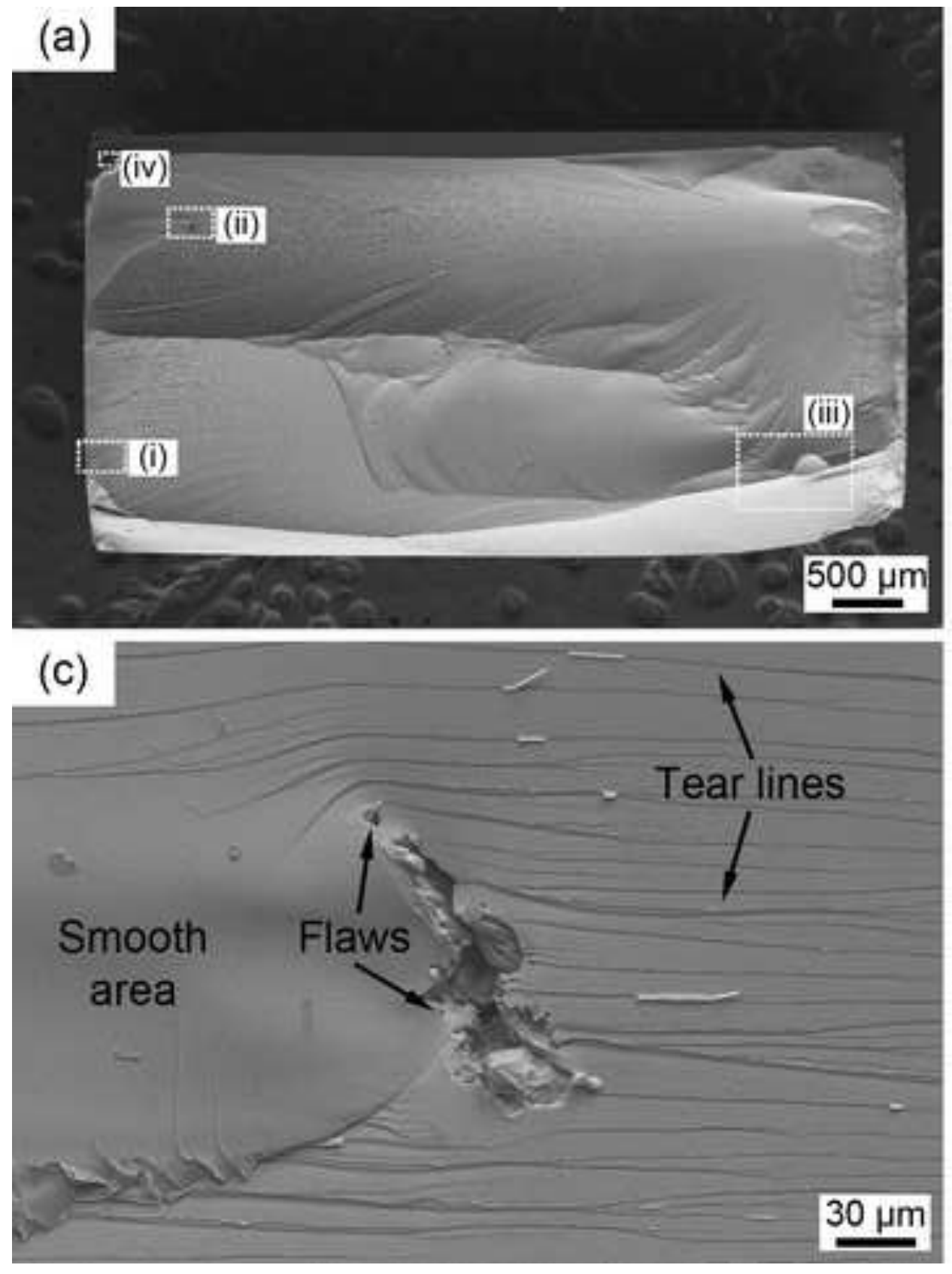

(c)

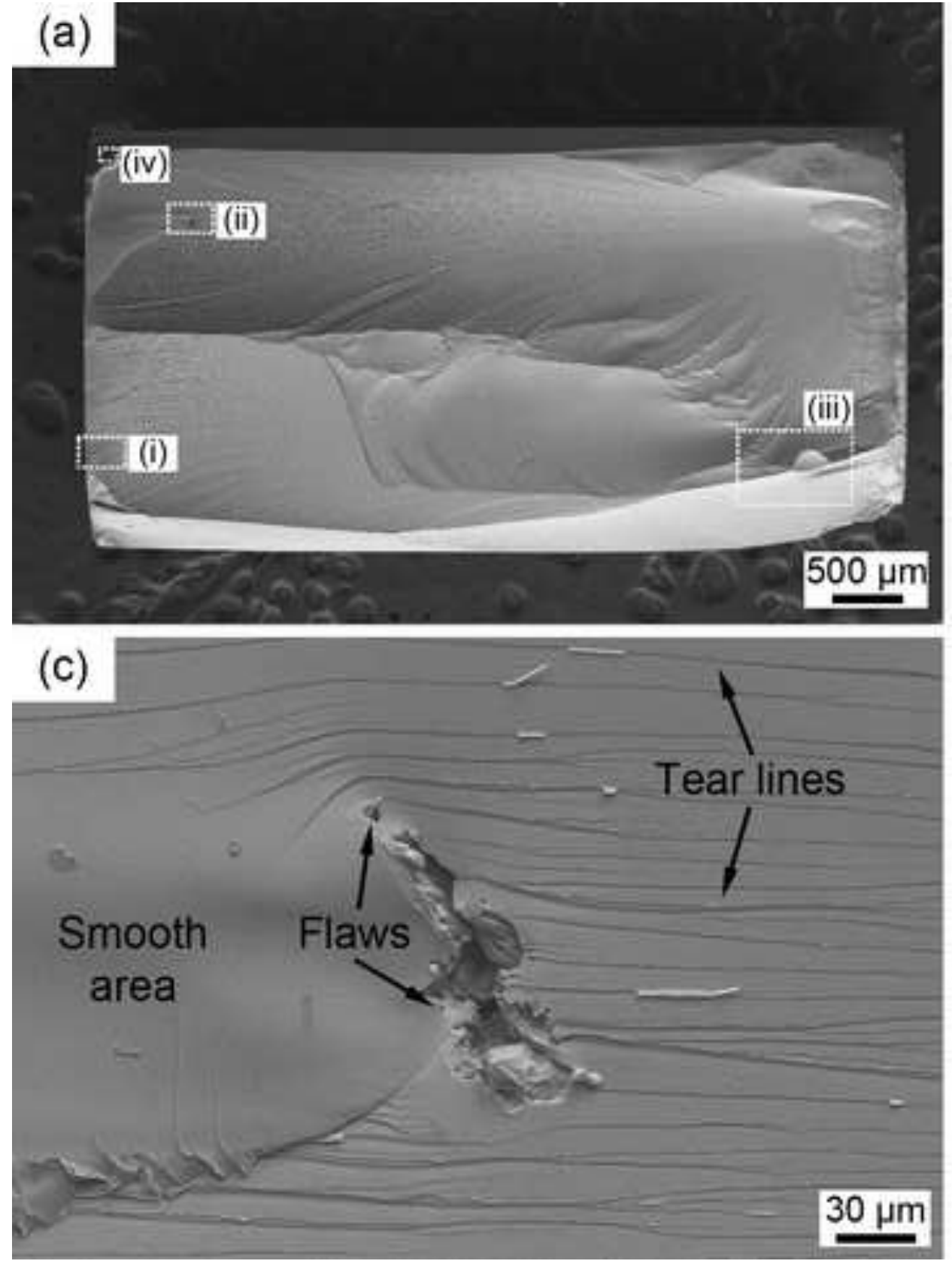

(b)

(d)

Corroded areas

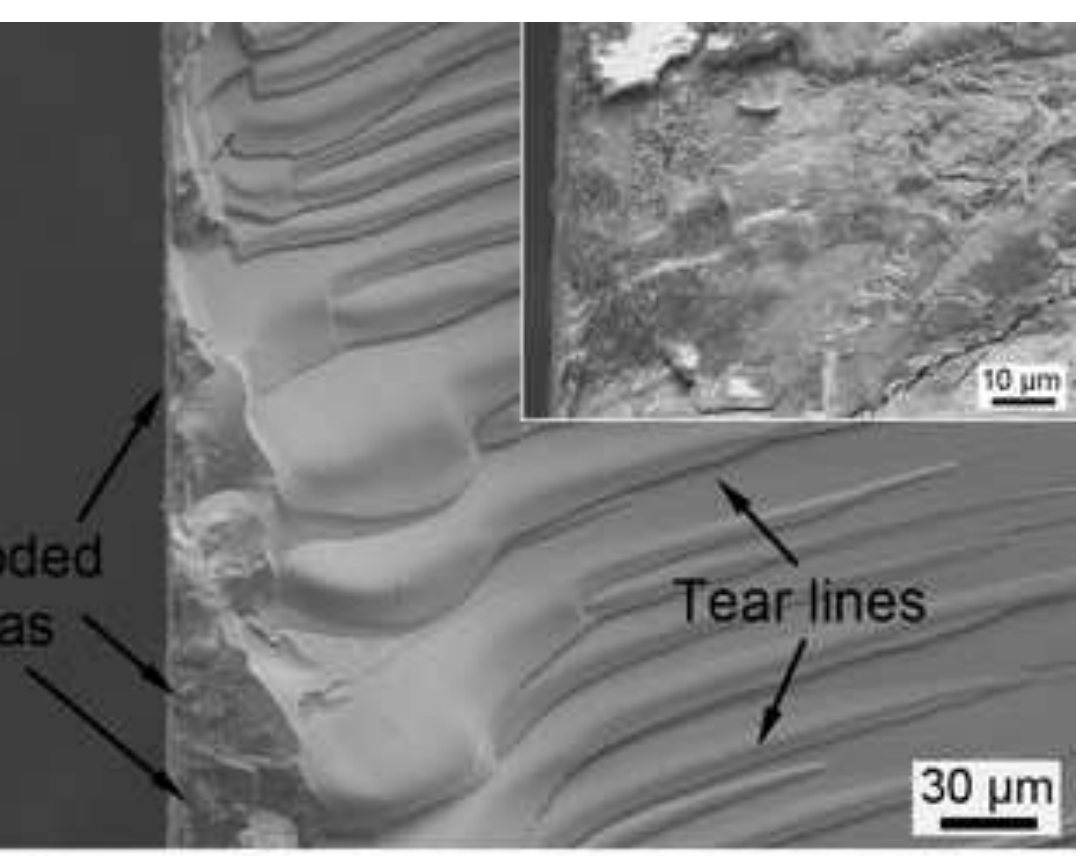
Microcracks

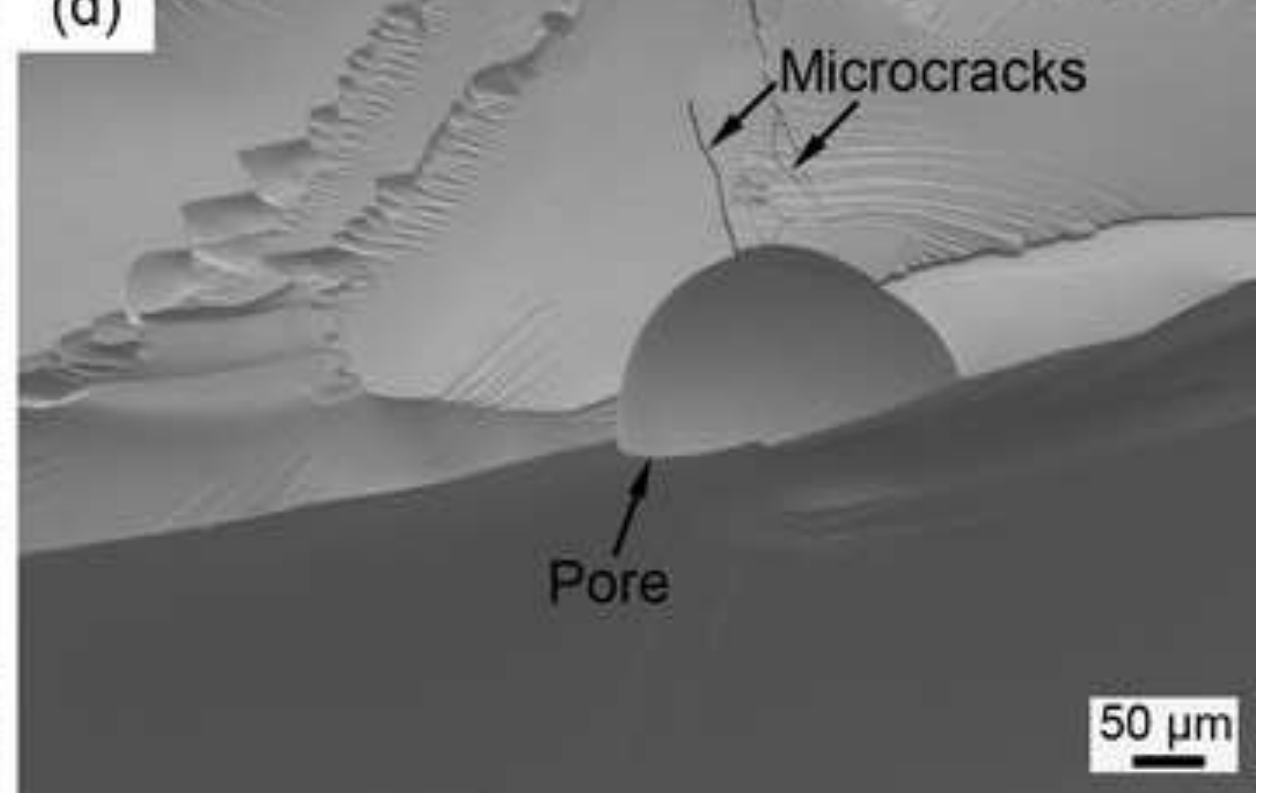




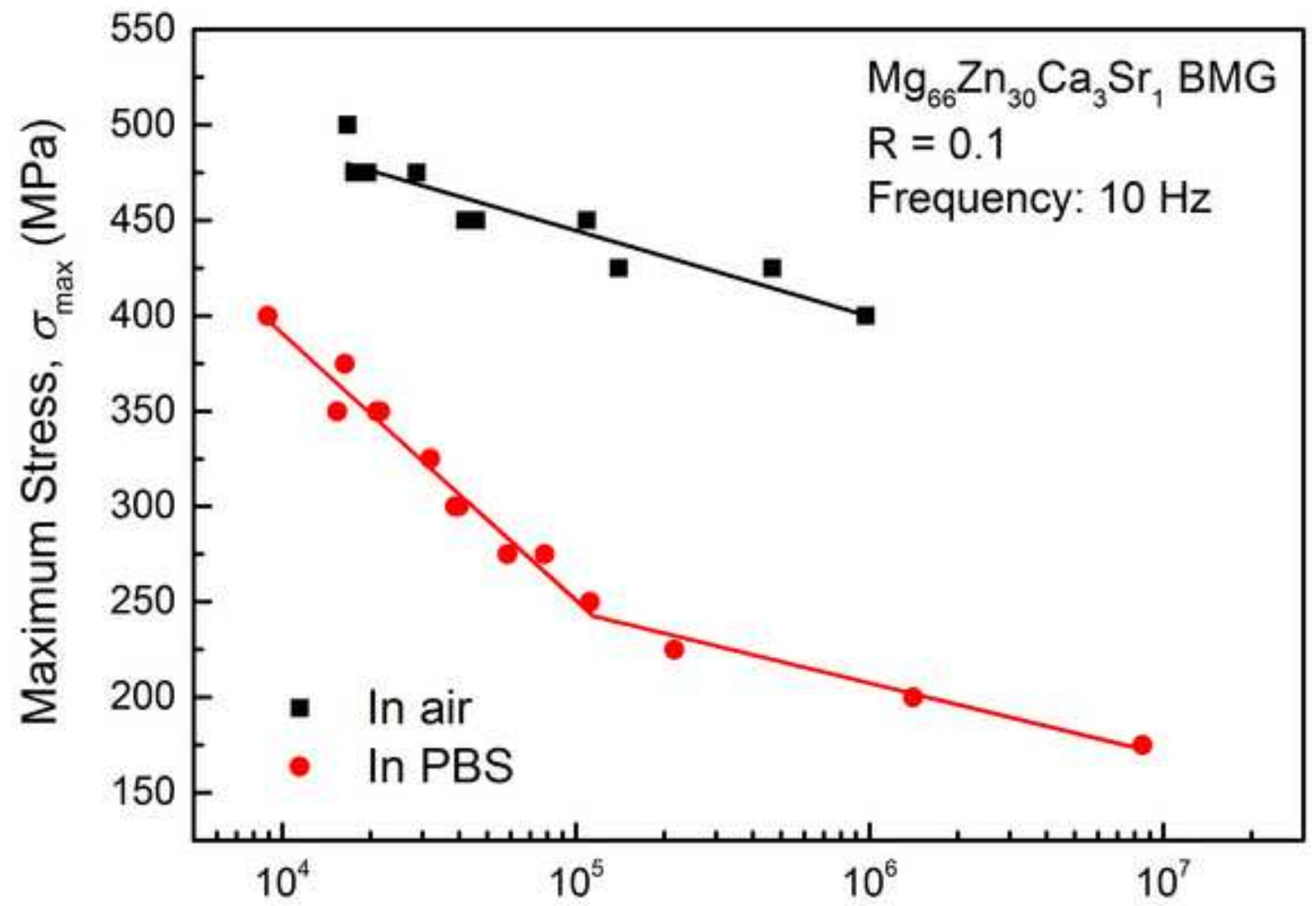

Number of Cycles to the First Major Peeling-off Fracture, $N_{p}$ 

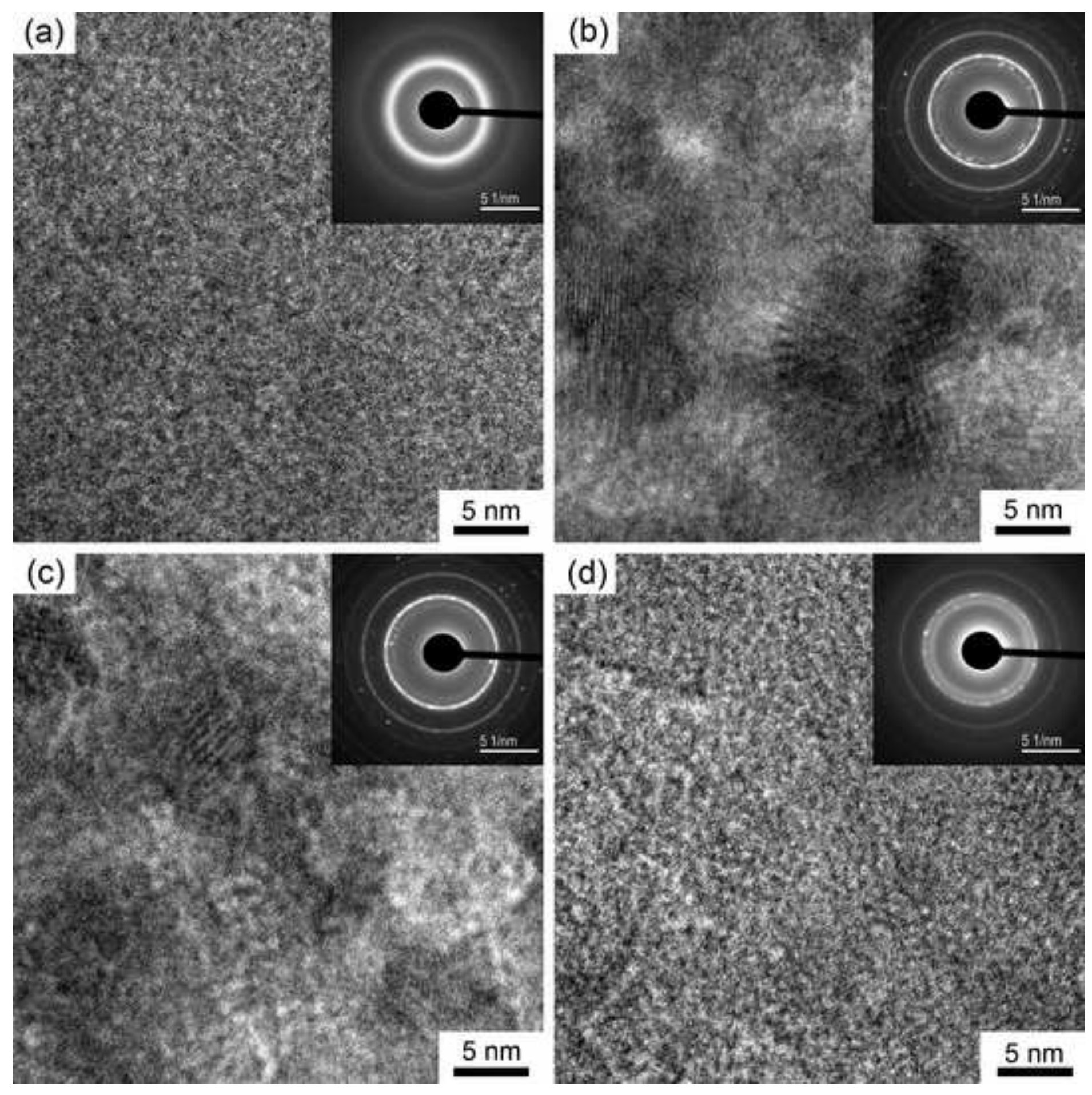


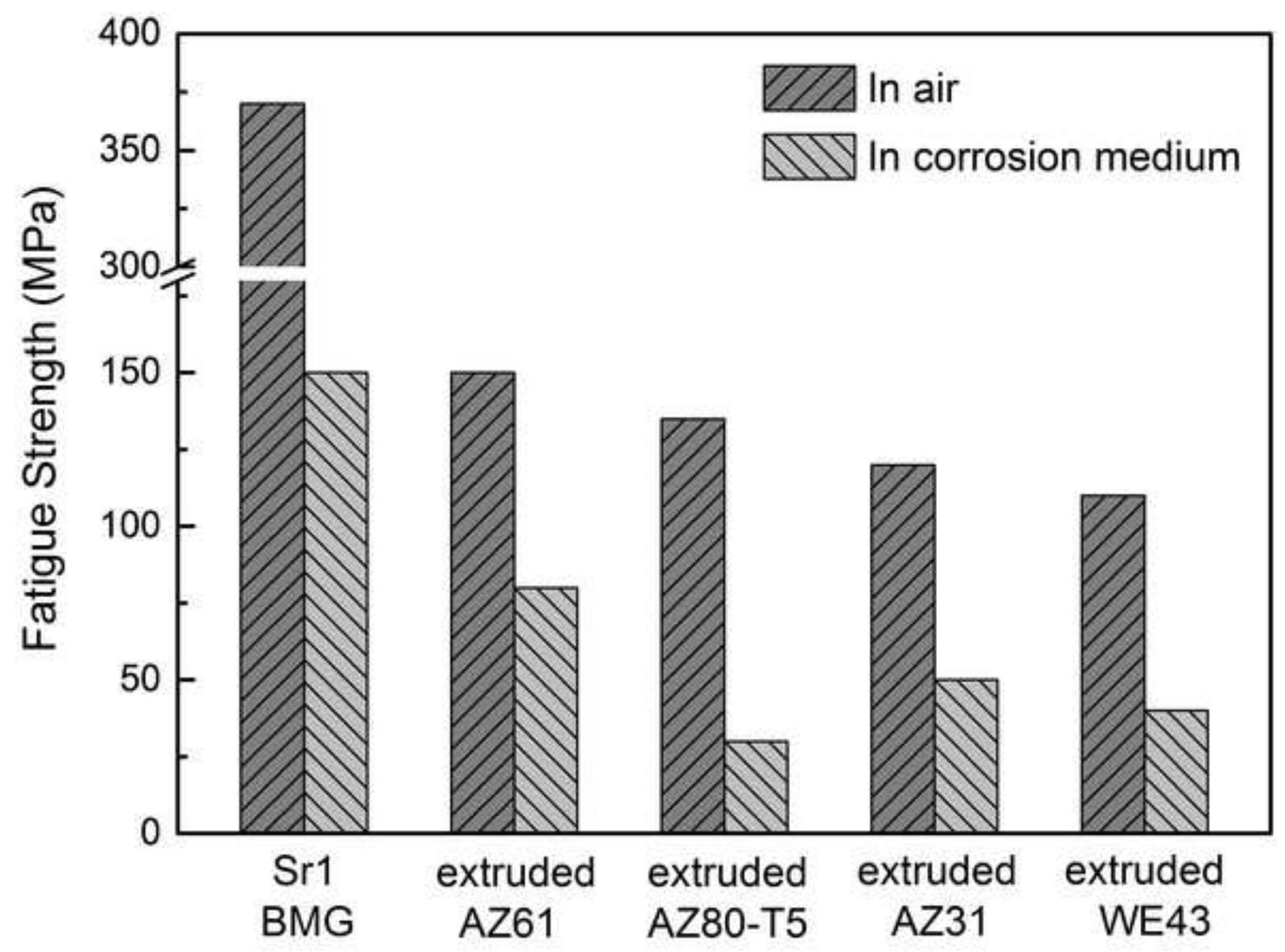




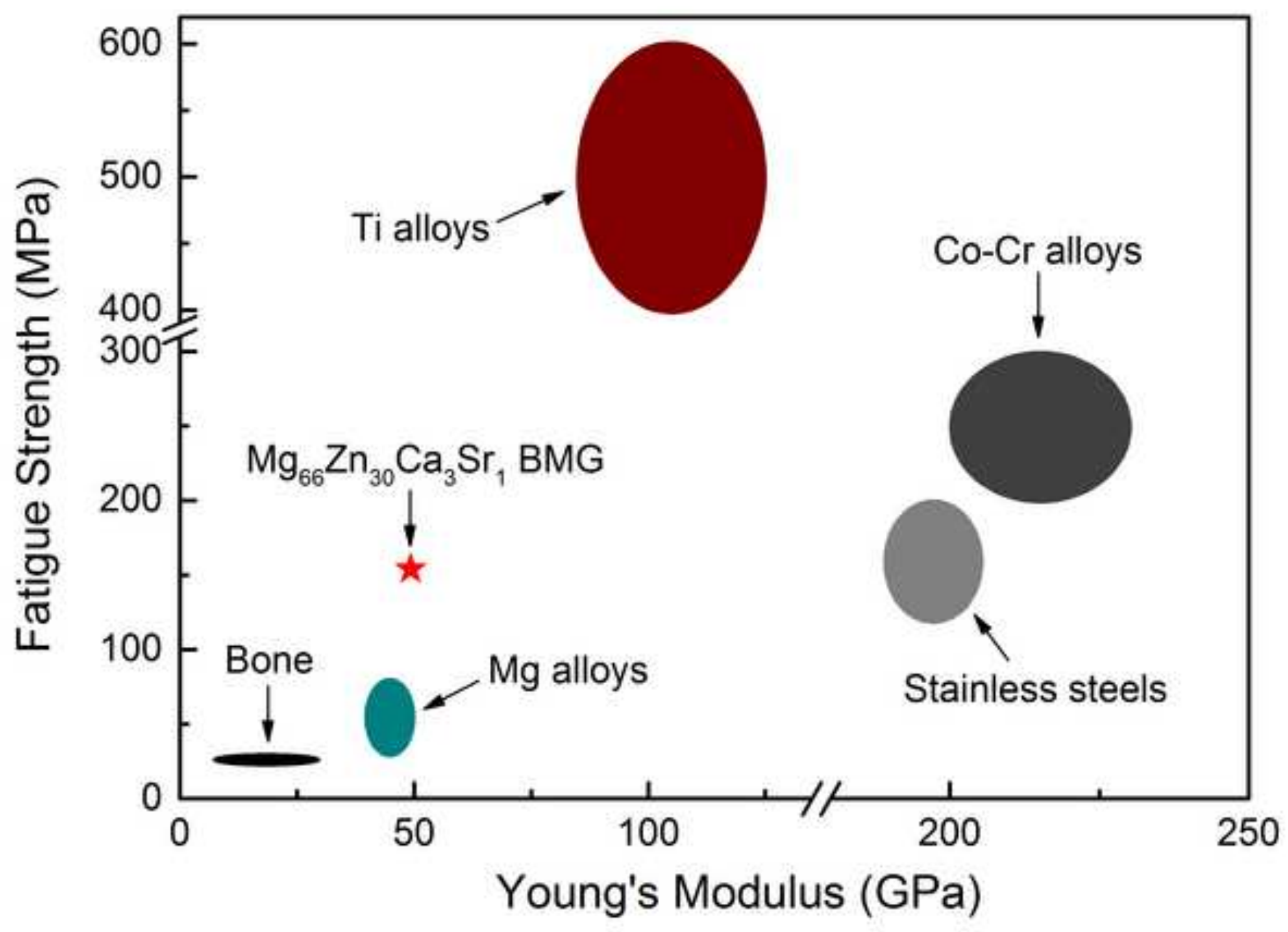

